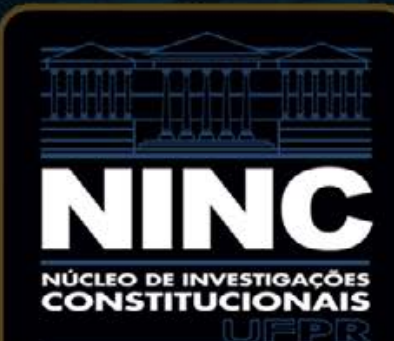




\title{
Aspectos constitutivos da teoria da argumentação jurídica: a contribuição de Robert Alexy*
}

\author{
Constituent aspects of the theory of legal \\ argumentation: the contribution of Robert Alexy
}

\author{
ROGÉRIO GESTA LEAL** \\ Universidade de Santa Cruz do Sul - UNISC (Brasil) \\ gestaleal@gmail.com \\ Recebido/Received: 22.01.2014 / January 22nd, 2014 \\ Aprovado/Approved: 13.02.2014 / February 13th, 2014
}

\section{Resumo}

O presente artigo estuda os aspectos constitutivos da teoria da argumentação jurídica, utilizando como principal objeto de análise o pensamento de Robert Alexy. Entre as relevantes dimensões da teoria da argumentação de Alexy, o estudo examina a teoria do balanceamento das normas jurídicas, as objeções a ela apresentadas e as respostas dadas pelo autor às críticas a ele dirigidas.

Palavras-chave: teoria da argumentação jurídica; Robert Alexy; ponderação de princípios jurídicos.

\begin{abstract}
This article studies the constituent aspects of the theory of legal argumentation, using as a main object of analysis the thought of Robert Alexy. Among the relevant dimensions of Alexy's theory of argumentation, the study examines the theory of balancing of legal principles, the objections presented to it and the answers given by the author to the critics directed at him.
\end{abstract}

Keywords: the theory of legal argumentation; Robert Alexy; balancing of legal principles.

Como citar este artigo | How to cite this article: LEAL, Rogério Gesta. Aspectos constitutivos da teoria da argumentação jurídica: a contribuição de Robert Alexy. Revista de Investigações Constitucionais, Curitiba, vol. 1, n. 2, p. 131-166, maio/ago. 2014. DOI: http://dx.doi.org/10.5380/rinc.v1i2.40513

* Este ensaio é fruto do projeto de pesquisa intitulado A DECISÃO JUDICIAL: ELEMENTOS TEÓRICO-CONSTITUTIVOS À EFETIVAÇÃO PRAGMÁTICA DOS DIREITOS FUNDAMENTAIS, desenvolvido junto ao Curso de Direito da UNOESC, bem como com o Grupo de Pesquisa sobre Teoria dos Direitos Fundamentais Sociais, desta mesma instituição, mais especialmente para o evento internacional Proporcionalidade, dignidade humana e direitos sociais na teoria dos direitos fundamentais de Robert Alexy, realizado nos dias 26 a 28 de março de 2013, junto ao Programa de Pós-Graduação em Direito - Mestrado, da UNOESC.

** Professor Titular da Universidade de Santa Cruz do Sul - UNISC (Santa Cruz do Sul-RS) e da UNOESC. Doutor em Direito do Estado pela Universidade Federal de Santa Catarina e Doutor em Direitos Humanos pela Universidad de Buenos Aires. Professor Visitante da Università Túlio Ascarelli - Roma Trè, Universidad de La Coruña - Espanha e Universidad de Buenos Aires. Professor da Escola Nacional de Formação e Aperfeiçoamento da Magistratura - ENFAM. Membro da Rede de Direitos Fundamentais-REDIR, do Conselho Nacional de Justiça-CNJ, Brasília. Coordenador Científico do Núcleo de Pesquisa Judiciária, da Escola Nacional de Formação e Aperfeiçoamento da Magistratura - ENFAM, Brasília. Membro do Conselho Científico do Observatório da Justiça Brasileira. Desembargador do Tribunal de Justiça do Estado do Rio Grande do Sul. 


\section{SUMÁRIO}

I. Notas Introdutórias. II. Notas sobre alguns precursores. III. O que tem Robert Alexy a dizer sobre a Teoria da Argumentação Jurídica? Aspectos gerais. IV. Considerações Finais. V. Referências

\section{NOTAS INTRODUTÓRIAS}

Historicamente tanto o formalismo como o positivismo constituem a grande marca metodológica também na área do Direito do século XX.

Todavia há alguns elementos de fragilização do argumento positivista em especial nos seguintes aspectos: (1) ele não admite lacunas e, quando o faz, não apresenta para elas qualquer solução material; (2) ele não tem meios para lidar com conceitos jurídicos indeterminados, com normas em branco e, em geral, com proposições carecidas de preenchimento com valorações; (3) ele se apresenta inoperacional em situações de tensões de princípios jurídicos; (4) ele detém-se perante a questão complexa mas inevitável das normas injustas.

Mas qual a alternativa à dogmática jurídica restrita que esta longa história do positivismo construiu? Muitas são as experiências e respostas no particular, razão pela qual, para o objeto deste trabalho, pretendo tão somente recuperar algumas discussões sobre estes temas para dirigir minha atenção à Teoria da Argumentação Jurídica, eis que ela vai contribuir em muito à compreensão e operacionalidade da decisão judicial, em face das suas particularidades epistemológicas e fenomenológicas constitutivas.

Por ser de igual sorte muito variadas as matrizes teóricas que tratam da teoria da argumentação jurídica, vou eleger a contribuição de Robert Alexy no particular, eis que tem dialogado com múltiplas fontes e referencias importantes deste universo problemático.

\section{NOTAS SOBRE ALGUNS PRECURSORES}

Um dos temas correlatos à Teoria da Argumentação Jurídica é com certeza a Teoria do Discurso, mais ligado antes à filosofia do que à ciência jurídica, mas que em seguida vão se comunicar e imbricar.

Em trabalho extremamente didático, Ernesto Laclau vai sustentar que um dos principais fundadores da Teoria do Discurso, Ferdinand de Saussure, já teve oportunidade de destacar que são elementos constitutivos necessários de qualquer fala e comunicação: (i) a língua (os tesouros da linguagem depositadas na mente do falante); a palavra (a experiência individual do uso da linguagem); (ii) significante (fluxo de sons) e o significado (conceito), os quais, juntos, constituem o signo, que, por sua vez, é a 
fundamental unidade de análise lingüística; (iii) o sintagma (enquanto relações de combinação entre os signos) e o paradigma (relações de substituição)'1.

A partir daqui, compreendia o mesmo autor francês que estariam norteando esta estruturação constitutiva dos discursos alguns princípios fundantes, a saber: (i) na linguagem não há termos positivos, mas somente diferenças entre termos (cada termo significa somente o que a linguagem determina através das diferenças com outros termos); (ii) a linguagem é somente forma, não substância, eis que cada termo está relacionado com outros termos somente através de leis de combinação e substituição os vinculando, independentemente dos seus conteúdos materiais.

Decorre daqui o que a literatura especializada chamou de Teoria da Hegemonia Lingüística, cujas regras de sustentação são as seguintes:

(a) Se as identidades em qualquer espaço de significação são diferenciadas, a totalidade de sistemas de diferenças está presente em todo e qualquer ato de significação; isto requer que o sistema - enquanto totalidade das razões destas diferenças - seja fechado, caso contrário se teriam infinitas dispersões nas quais a significação não seria possível;

(b) Esta totalidade sistêmica, entretanto, requer limites, e estes somente são visíveis se se pode ver o que está além deles; este além, por sua vez, só pode constituir mais diferenças e, como o sistema é o sistema de todas as diferenças, não haveria verdade ou segurança neste além. Isto tornaria impossível a decisão entre internalidade e externalidade.

(c) A única saída para este dilema é se aquele além tivesse a característica da exclusão, ou seja, não fosse mais um elemento presente no cenário descrito, mas o antagônico em face do que está sendo considerado como interno ao fenômeno estudado, e, portanto, tomado como enemy which makes possible the unity of all the forces opposed to it 2 .

(d) Tudo isto se complica quando se levam em conta aqueles elementos que não são necessariamente diferentes, mas equivalentes no processo lingüístico de formação de discursos, pois que fragiliza aquela idéia de sistema fechado e completo de significantes e significados, revelando-se impossível o seu objeto, eis que toda a identidade está constituída em torno da insolúvel tensão entre diferença e equivalência 3 .

(d) A centralidade das relações hegemônicas na teoria do discurso vem do fato que o desejo de plenitude está sempre presente, todavia este mesmo desejo é inalcançável, somente podendo existir em torno de particularidades as quais assumem, temporariamente, o papel de encarná-lo. Isto explica porque equivalência e diferença - que

\footnotetext{
1 LACLAU, Ernesto. Philosophical roots of discourse theory. New York: Oxford University Press, 2001.

2 LACLAU, Ernesto. Philosophical roots of discourse theory. New York: Oxford University Press, 2001. p.15.

3 Neste sentido ver o trabalho de BARTHES, Roland. Empire of Signs. New York: Hill and Wang, 1982.
} 
em linhas gerais corresponde ao que se chamou antes de combinação e substituição na análise lingüística - são as duas dimensões da vida política.

Ocorre que o estruturalismo lingüístico francês ainda apresenta, no mínimo, duas falhas: (i) primeira, a de que, para Saussure, a lingüística do discurso - concebida como unidade lingüística que independe da sentença produzida por este discurso - era impossível dado que a concatenação de sentenças dependia dos caprichos dos falantes, não podendo ser submetida a qualquer regularidade estrutural. Em face disto, a possibilidade de transição de um nível lingüístico senso estrito para uma semiologia mais generalizada (enquanto ciência dos signos em sociedade), a qual foi também parte do projeto de Saussure, foi severamente limitada; (ii) segunda, a de que há um estrito isoformismo entre significante e significado (o que significa que um e somente um conceito corresponde a cada fluxo de sons), todavia, o princípio estrito de que a linguagem é forma e não substância significa que uma diferença de pura substância entre som e conceito deveria ser ignorada. De outro lado, sob o ponto de vista da forma, no sentido do referido isomorfismo, em que o significante e o significado se transformam indistintamente na noção de signo, entra em colapso 4 .

Assim é que This linguistic formalism, by breaking the link between linguistic categories and the substance that we call speech, made possible the extension of structural analysis to the ensemble of social life and opened the way to a generalised semiology, as the one practised by Barthes and others since the 1960s5.

Na década de 1960 tem-se certa transição do estruturalismo lingüístico para outra dimensão, que é o que se pode chamar de pós-estruturalista, no sentido de problematizar aquela forma de totalidade fechada com a qual o estruturalismo tomava as expressões gramaticais isoladas entre si, fazendo com que autores como Roland Barthes sustentassem, de forma bastante crítica, ser inapropriado separar conotação de denotação no âmbito das expressões lingüísticas veiculadas em frases de contextos múltiplos, eis que faces distintas do mesmo fenômeno que é a linguagem na comunicação (associa-se aqui a lógica lacaniana do significante, concebendo esta separação como verdadeiro obstáculo para o aclaramento do signo em seu sentido contextual). 6

Na verdade, a lingüística, a partir de Saussure, toma a língua como seu objeto, quase sempre sem ultrapassar a dimensão da frase. $O$ interesse pelo texto como um todo, principalmente com o desenvolvimento dos estudos de semântica, e a aceitação

\footnotetext{
4 Kress, Gunther. From Saussure to critical sociolinguistics. In WETHERELL, Margaret. Discourse Theory and Practice: A Reader. London: Sage Publications, 2001, p.29 e seguintes.

5 Idem, p.04.

6 Ver o já clássico texto de BARTHES, Roland. The Pleasure of the Text. New York: Hill and Wang, 1975.
} 
do fato de o texto não ser, como já se sabe há muito, a simples soma de frases, tornou necessária uma lingüística do texto ou do discurso7.

A par dos evolveres históricos e epistemológicos sobre estas questões, é no final da década de 1990, conforme alerta de James E. Herget ${ }^{8}$, estudioso da cultura germânica, que surgem as principais correntes do debate mais crítico sobre os pontos destacados: a "teoria do discurso", "a teoria retórica", a "teoria dos sistemas" e o "positivismo legal institucionalista". Conclui o autor também que, no que tange à teoria do discurso do direito e da democracia, os trabalhos de Jürgen Habermas, Robert Alexy e Klaus Günther são expressão qualitativa do debate.

\section{O QUE TEM ROBERT ALEXY A DIZER SOBRE A TEORIA DA ARGUMENTAÇÃO JURÍDICA? ASPECTOS GERAIS.}

A produção de Robert Alexy é extremamente rica em termos de reflexão e aplicação normativa, razão pela qual não pretendo esgotá-la - até porque se trata de autor vivo, em plena produção científica -, mas me apropriar, de forma coerente, de algumas contribuições do autor para o tema que interessa aqui, a saber, formas de qualificação e fundamentação da decisão judicial, no âmbito do que se pode chamar de Teoria do Discurso e da Argumentação Jurídica.

Desde o seu já clássico trabalho sobre teoria da argumentação jurídica, o autor alemão refere que a lógica formal e tradicional de interpretação e aplicação do direito não atende muitas vezes situações em que: (a) a imprecisão da linguagem do Direito dificulta a interpretação/aplicação; (b) há conflitos entre normas; (c) inexistam normas jurídicas que se amoldem a casos de alta complexidade temática; (d) casos especiais demandem decisões que contrariem textualmente estatutos normativos ${ }^{9}$. Decorre daqui a possibilidade material de que os âmbitos decisionais no tocante a casos concretos tenham carga discricional e subjetiva ampliadas, afigurando-se urgente a demarcação de parâmetros e ferramentas de controles para tanto, dentre os quais, toma relevo, na obra de Alexy, a argumentação jurídica. Para tal desiderato,

existe uma necessidade de estudos analíticos da estrutura do argumento em decisões particulares e em discussões científicas, das regras que são seguidas e das formas de argumentação que são usadas em diferentes áreas da lei, da estrutura da argumentação na série de decisões, e da estrutura da argumentação nos processos. Estas investigações

\footnotetext{
7 Ver neste sentido o trabalho de BARROS, Diana Luz Pessoa de. Teoria do Discurso: fundamentos semióticos. São Paulo: Humanitas/USP, 2002.

8 HERGET, James E. Contemporary German Legal Philosophy. Philadelphia: University of Pennsylvania Press, 1996.

9 ALEXY, Robert. Teoria da Argumentação Jurídica: a teoria do discurso racional como teoria da justificação jurídica. São Paulo: Landy, 2001, p.17.
} 
analíticas teriam de ser suplementadas por estudos empíricos do comportamento da tomada de decisões 10 .

Vale a lembrança de Tarello sobre a importância da utilização de argumentos jurídicos mais sofisticados e eficientes diante da complexidade crescente das relações sociais, notadamente os que se utilizam da valoração dos princípios no sistema normativo:

Tuttavia l'utilizzazione di questo tipo di norme nell'argomentazione giuridica era per lungo tempo rimasta alquanto marginale, a tutto vantaggio di altre tecniche di argomentazione giuridica ritenute maggiormente in grado di assicurare al lavoro del giurista, e del giudice in particolare, un'aura di meccanicità formalistica, di mera esecuzione tecnica del precetto del legislatore - e solo di quello - a tutto vantaggio della separazione dei poteri e della certezza del diritto. ${ }^{11}$

Esta nova perspectiva coloca em cena - com o papel dos princípios jurídicos nos sistemas normativos - revisão profunda da relação entre direito e moral, bem como a necessidade de rejeitar, ou ao menos reconfigurar, o paradigma juspositivista que até a pouco vinha marcando tal distinção de forma abrupta e artificial, introduzindo na teoria da argumentação jurídica novos instrumentos de análise (diferentes do paradigma lógico-dedutivo do silogismo hegemônico), única forma de se dar conta das múltiplas lógicas aplicativas aos princípios ${ }^{12}$.

Daí a defesa de Alexy de uma teoria normativa a qual permita que seja feito pelo menos algum tipo de medida de potência dos diferentes argumentos e da racionalidade da argumentação jurídica, advertindo, então, que a teoria do discurso jurídico racional é criada pela incorporação da teoria do discurso prático geral à teoria do sistema jurídico. Essa incorporação não é mera aplicação da teoria geral do discurso ao Direito, mas

\footnotetext{
10 Idem, p.37.

11 TARELLO, Giancarlo. L'interpretazione della legge. Milano: Giuffrè, 2010, p. 384. Aduz ainda o autor que o fenômeno do constitucionalismo do século XX vai mudar este cenário, no sentido de que: Com'è noto, le cose sono molto cambiate a partire dalla seconda metà del Novecento, specialmente con la promulgazione in molti paesi occidentali di costituzioni lunghe, rigide e garantite: costituzioni che contengono cataloghi di diritti e principi fondamentali, e che sono (o comunque sono pensate per essere) dotate di una forza normativa e assiologica superiore alla legge ordinaria. II "nuovo" diritto costituzionale, il diritto costituzionale della seconda metà del Novecento, è diventato così un diritto "per principi.

12 A despeito das tentativas neo-positivistas de encampação deste debate pelo argumento de que: regole $e$ principi non sono affatto cose diverse, ma sono solo gradazioni diverse di una stessa realtà, di una stessa tecnica regolatoria, pertanto descrivibili ed analizzabili con gli strumenti disponibili ad una riflessione teorica di stampo giuspositivista. PINO, Giornio. Principi e argomentazione giuridica. Milano: Giuffrè, 2008, p.48. Lembra o autor que um dos defensores desta tese é MACCORMICK, Neil. Ragionamento giuridico e teoria del diritto. Torino: Giappichelli, 2001.
} 
produz desdobramentos necessários à fundamentação sistemática deste13. Em verdade, para o autor, o ponto comum entre discurso jurídico e discurso prático é que em ambos há a preocupação com a correção das afirmações normativas.

Em tal conceito pode-se perceber, divergindo de Atienza, que a pesquisa de Alexy, a despeito de estar vinculada aos debates filosóficos sobre a ética do discurso, não pode ser reduzida a uma sistematização e reinterpretação da teoria do discurso prático habermasiana e, por outro lado, uma extensão dessa tese para o campo específico do direito ${ }^{14}$.

Ocorre que a decisão judicial é sempre veiculada pelas escolhas/preferências do decisor - conscientes ou inconscientes -, o que reclama, ao menos para a Teoria da Argumentação Jurídica, aferições condizentes às razões de justificação e fundamentação qualitativa destas escolhas e preferências, bem como daquelas alternativas que não foram eleitas, o que implica juízos de valor.

Em face disto uma pergunta se impõe à Alexy: A pergunta é, onde e até que ponto são necessários os julgamentos de valor, como deve ser determinado o relacionamento entre esses julgamentos de valor e os métodos de interpretação jurídica, bem como as proposições e conceitos de dogmática jurídica, e como esses julgamentos de valor podem ser racionalmente fundamentados ou justificados 15 .

Em texto bastante elucidativo o autor faz questão de demarcar algumas matrizes de interpretação e aplicação do direito que abordam diretamente e indiretamente estas questões e que foram e ainda são importantes, identificando-as como segue:

(1) A Matriz Deducionista, que opera com a lógica de que a decisão de qualquer caso jurídico decorre necessariamente de normas válidas, juntamente com definições de conceitos jurídicos, os quais são pressupostos como certos, deixando de considerar - e por isto falha - questões como a imprecisão da linguagem das normas, a possibilidade de conflitos ou colisões entre normas, o fato de que possa não haver uma norma para a decisão de um determinado caso e a possibilidade de um desenvolvimento do Direito contrário à formulação literal de uma norma16. Ocorre que tal perspectiva es-

13 ALEXY, Robert. A argumentação jurídica como discurso racional. In: TEIXEIRA, Anderson Vichinkeski; OLIVEIRA, Elton Somensi de Oliveira (Orgs.). Correntes Contemporâneas do Pensamento Jurídico. São Paulo: Manole, 2010, p.07.

14 ATIENZA, Manuel. As razoes do direito. Teorias da Argumentação Jurídica. São Paulo: Landy, 2000, p. 234. Ver também os textos de: COLEMAN, John. La pratica dei principi. In difesa di un approccio pragmatista alla teoria del diritto. Bologna: II Mulino, 2006; e VIOLA, Francesco \& ZACCARIA, Giancarlo. Diritto e interpretazione. Lineamenti di teoria ermeneutica del diritto. Roma-Bari: Laterza, 2009.

15 É interessante que Alexy lembra que esta é uma constatação bastante convergente em nível de teoria do direito, citando para tanto autores como Karl Larenz, Friedrich Müller, Kriele, Engisch, dentre outros. In ALEXY, Robert. Teoria da Argumentação Jurídica: a teoria do discurso racional como teoria da justificação jurídica. Op.cit., p.20.

16 Neste ponto o autor cita WINDSCHEID, Bernhard. Lehrbuch des Pandektenrechts, p.111:Die Endentscheidung ist das Resultat einer Rechnung, bei welcher die Rechtsbegriffe die Faktoren sind.(„A decisão final é o resultado do 
quece que a lei escrita não cumpre a tarefa de prover uma justa resolução dos problemas legais. Nesses casos, a decisão judicial fecha a brecha de acordo com os padrões da razão prática e dos conceitos de justiça bem fundamentados da comunidade ${ }^{17}$.

(2) A Matriz Decisionista, segundo a qual o juiz, se estiver fundado em boas razões, como leis e precedentes, deve decidir de acordo com os padrões extrajurídicos. Lembra Alexy que tal postulado fora já formulado por Hans Kelsen, quando afirmava que, em casos difíceis, o juiz, como um legislador, deverá resolver um problema de política jurídica ${ }^{18}$.

(3) A Matriz Hermenêutica, representada na opinião de Alexy por autores como Gadamer e Betti, e na jurisprudência alemã por Larenz, Kaufmann e Esser, à qual existe uma estrutura de interpretação e compreensão em toda a aplicação da norma jurídica, e o seu conceito chave é o de círculo hermenêutico que, na jurisprudência, conta com três dimensões. Nas palavras do próprio autor:

O primeiro concerne à relação entre o chamado preconceito e o texto. O preconceito é uma hipótese da qual parte o intérprete quando entra em contato com um texto. Essa hipótese expressa a suposição do intérprete ou sua expectativa quanto à solução correta para o problema jurídico a ser decidido. Seu conteúdo é determinado pela concepção geral de sociedade que o intérprete possui e por suas experiências profissionais. A imagem do círculo se destina a salientar a interação entre o texto da norma e a hipótese de interpretação. Por um lado, sem uma hipótese de interpretação, o texto da norma não pode sequer ser tido como problemático ou não problemático. Por outro lado, a hipótese de interpretação deve ser analisada com base no texto da norma e com a ajuda das regras da metodologia jurídica. O ponto decisivo é que a teoria do círculo hermenêutico, como tal, não diz nada sobre os critérios de afirmação ou rejeição da hipótese de interpretação. Essa pergunta só pode ser decidida com base em argumentos. Isso já demonstra que a teoria do círculo hermenêutico não pode substituir uma teoria da argumentação jurídica. Isso não é, no entanto, desprovido de valor. ${ }^{19}$

cálculo no qual os conceitos jurídicos são os fatores“); KOCH, Hans- Joachim \& RüSSMAN, Helmut. Juristische Begrúndungslehre, p.48 e segs. e 112; NEUMANN, Ulfrid. luristische Argumentationslehre, p.16 e segs.

17 Palavras do Tribunal Constitucional Alemão, citado por ALEXY, Robert. Teoria da Argumentação Jurídica: a teoria do discurso racional como teoria da justificação jurídica. Op.cit., p.34.

18 Cita Alexy aqui a obra de AUSTIN, John. Lectures on jurisprudence or the philosophy of positive law. A citação de Kelsen a que faz referência, diz estar no KELSEN, Hans. Reine Rechtslehre, p. 350. In ALEXY, Robert. A argumentação jurídica como discurso racional. Op.cit., p.03.

19 ALEXY, Robert. A argumentação jurídica como discurso racional. Op.cit., p.04. Avança o autor dizendo que: $O$ mesmo é verdade para os outros dois tipos de círculos hermenêuticos. A segunda proposta se refere à relação entre a parte e o todo. Por um lado, para compreender uma norma, é necessário compreender o sistema de normas ao qual ela pertence; de outra sorte, não é possível compreender um sistema de normas sem compreender as normas específicas pelas quais o sistema é constituído. Novamente, encontramos, aqui, apenas a formulação de um problema, mas nenhum critério é oferecido para sua solução. O problema reside na criação de unidade ou de 
Retira o autor daqui a conclusão de que, embora a matriz hermenêutica ofereça importantes descobertas sobre a estrutura da interpretação jurídica, não é suficientemente uma solução para o problema da correta interpretação, isto porque: $A$ justeza de uma interpretação só pode ser provada quando forem determinadas as razões em seu favor e rejeitados os motivos que a ela se opõem. Portanto, a frase "interpretação é argumentação" torna-se verdade20.

(4) A Matriz Coerencial, que Alexy associa à da Integridade, vem trabalhada por Carl Friedrich von Savigny e por Ronald Dworkin, o primeiro, com a tese do conjunto orgânico e da interdependência interna, ou relação pela qual os conceitos jurídicos individuais e as regras são feitas em uma unidade de maiores dimensões ${ }^{21}$; o segundo, exigindo do decisor judicial que ele se pergunte sempre se suas deliberações poderiam fazer parte de uma teoria coerente que justifique a rede normativa como um todo integrado e orgânico22. Contesta tais posições sustentando que uma matriz hermenêutica/ aplicativa do Direito na qual a coerência é apenas - ou talvez o mais importante e, portanto, o mais decisivo - critério para a correção da interpretação, teria como conseqüência representar a idéia de holismo jurídico, segundo a qual todas as premissas já estão incluídas, ou escondidas, no sistema jurídico, e só precisam ser descobertas ${ }^{23}$.

A partir destes referenciais é que Alexy começa a fundamentar a importância de uma Teoria do Discurso Jurídico, trabalhando com a lógica de que:

Qualquer um pode racionalmente discutir sobre questões práticas, tendo, com isso, uma pretensão de correção. Assim, por um lado, a teoria do discurso tenta buscar um equilíbrio entre as teorias objetivistas e cognitivistas e, por outro, entre teorias subjetivistas e não cognitivistas. Discursos práticos gerais não são argumentações institucionalizadas sobre o que é obrigatório, proibido ou permitido, ou sobre o que é bom ou ruim. Um discurso prático é racional se preenche as condições da argumentação racional prática. Se

coerência. Essa é a tarefa da argumentação sistêmica. Pode-se chamar o postulado por trás do segundo círculo de postulado de coerência.

${ }^{20}$ ALEXY, Robert. A argumentação jurídica como discurso racional. Op.cit., p.04. Avança o autor dizendo que: $O$ mesmo é verdade para os outros dois tipos de círculos hermenêuticos. A segunda proposta se refere à relação entre a parte e o todo. Por um lado, para compreender uma norma, é necessário compreender o sistema de normas ao qual ela pertence; de outra sorte, não é possível compreender um sistema de normas sem compreender as normas específicas pelas quais o sistema é constituído. Novamente, encontramos, aqui, apenas a formulação de um problema, mas nenhum critério é oferecido para sua solução. O problema reside na criação de unidade ou de coerência. Essa é a tarefa da argumentação sistêmica. Pode-se chamar o postulado por trás do segundo círculo de postulado de coerência.

21 Referindo no particular a obra SAVIGNY, Friedrich Carl von. System des heutigen römischen Rechts, p.XXXVI e segs.; e Vom Beruf unserer Zeit for Gesetzgebung und Rechtswissenschaft.

22 Citando como referência os trabalhos de: (a) DWORKIN, Ronald. Law's empire, p.245, e de (b) GÜNTHER, Klaus. Ein normativer Begriff der Kohärenz für eine Theorie der juristischen Argumentation, p.175 e segs. e p.181.

23 ALEXY, Robert. A argumentação jurídica como discurso racional. Op.cit., p.06. 
essas condições forem satisfeitas, o resultado do discurso estará correto. Uma teoria do discurso é, portanto, uma teoria procedimental da correção prática. ${ }^{24}$

Mas quais são as condições dos discursos racionais práticos? O autor adota aquelas referidas por Habermas, a saber, constituídos por argumentos morais, éticos e pragmáticos, e justifica sustentando que um tão amplo conceito de discurso prático é necessário porque, na prática, entre esses três tipos de razão prática existe não apenas uma relação de suplementariedade, mas também de interpenetração.

Estes argumentos além de constituir o que se aceita como discursos racionais práticos, também vão garantir a possibilidade de visibilidade e controle público tanto das formas de suas legitimações (aspectos constitutivos dos próprios argumentos), como dos processos de comunicação que os utilizam à tomada de decisões. Em termos gerais e históricos, o autor classifica os argumentos jurídicos da seguinte forma:

Os argumentos que possam ser eventualmente empregados na fundamentação jurídica podem ser classificados de diversas formas. A escolha da classificação depende, basicamente, da finalidade perseguida. Para nossos objetivos, pode-se fazer uma distinção em quatro categorias: linguística, genética, sistêmica e a dos argumentos práticos gerais. Argumentos linguísticos são baseados na verificação de uma linguagem usual factualmente existente. Muitas vezes, principalmente naquele grande número dos chamados casos simples, conduzem a um resultado definitivo. Então, a decisão é definida, e qualquer outra decisão só será possível se a lei for desenvolvida contra a literalidade do texto. No entanto, muitas vezes somente nos é possível afirmar que a norma é vaga ou, de certa forma, equivocadamente definida. Assim, uma decisão só poderá ser justificada mediante o auxílio de outros argumentos. Argumentos genéticos visam os propósitos factuais perseguidos pelo legislador histórico. Muitas vezes, eles não são aplicáveis porque não podem ser encontrados ou porque são demasiadamente vagos ou contraditórios. Além disso, o poder do argumento genético é discutível, como mostra a controvérsia entre a teoria subjetiva e a objetiva quanto ao escopo da interpretação. Argumentos sistêmicos são baseados na idéia da unidade ou coerência do sistema jurídico. Eles representam o correto ponto central do pensamento expressado, um pouco exageradamente, no modelo coerencial. Eles podem ser divididos em oito subgrupos que apenas podem ser definidos, mas não explicados aqui: (1) os argumentos que garantem a consistência, (2) o contextual, (3) os argumentos sistemático-conceituais, (4) os argumentos de princípio, (5) os argumentos jurídicos especiais, como a analogia, (6) os argumentos do precedente, (7) os históricose (8) os comparativos. Argumentos práticos gerais formam a quarta categoria. Eles podem ser divididos em argumentos teleológicos e deontológicos. Argumentos teleológicos são orientados para as conseqüências de uma interpretação e

24 Idem, p.07. 
baseados em uma idéia do que é bom. Argumentos deontológicos expressam o que é legalmente certo ou errado sem olhar as conseqüências. ${ }^{25}$

Para além da discussão das regras da argumentação racional - que remetem sempre aos argumentos -, a Teoria do Discurso ainda pretende propor um segundo nível de operação a essa primeira etapa: o nível das regras que se referem ao processo do discurso, no caso, aqui, do discurso jurídico. Nas palavras de Maniaci:

Secondo Alexy una tesi normativa p è razionalmente giustificata se e solo se è il risultato di una procedura argomentativa razionale, una procedura, cioè, le cui regole devono essere adempiute perché p possa dirsi razionalmente avanzato. Possiamo dire, in tal senso, che le regole di carattere procedurale elaborate da Alexy sono espressione di una razionalità discorsiva, tale in quanto va al di là, inglobandola, della mera razionalità logica. $E^{\prime}$ altrettanto pacifico che una delle regole più importanti della procedura argomentativa razionale sia il c.d. principio di universalizzabilità. 26

Por certo que esta perspectiva se associa à chamada distinzione forte fra principi e regole, no sentido de reconhecer que existem determinadas características constantemente exibidas dos princípios, as quais se afiguram necessárias e suficientes para distingui-los das regras jurídicas, a saber: (a) são normas particularmente importantes pelo fato de representarem valores fundantes e constitutivos do ordenamento, razão pela qual a relação que se impõe a eles é a aderência, enquanto as regras se obedecem; (b) os princípios têm graus de generalidade e vagueza muito amplos, com certa indeterminação, enquanto que as regras são normas que conectam conseqüências jurídicas a uma precisa fatispécie, associando uma modalidade deôntica (proibição, permissão ou obrigação) a certa conduta; (c) a aplicação dos princípios está condicionada a considerações de peso e importância, enquanto que as regras não poderiam ser operadas a partir desta lógica, mas deveriam ou não ser aplicadas27. Nas palavras de Maniaci:

25 Idem, p.11. Vale o destaque que o autor dá aos argumentos de princípios: Mais importantes, em nosso contexto, são os argumentos de princípio. Nos Estados democráticos constitucionais, os argumentos de princípio são essencialmente baseados em princípios constitucionais. Nos casos difíceis, sua aplicação regular inclui um balanceamento (Abwägung), mostrando, assim, que os princípios têm caráter de comandos que devem ser otimizados.

26 MANIACl, Giorgio. Note sulla teoria del bilanciamento di Robert Alexy. In Rivista Diritto\&questioni pubbliche, vol. 2, agosto 2002. Palermo: Università degli Studi di Palermo, 2002, p.02. Lembra o autor aqui que: Il principio di universalizzabilità, se inteso nella sua versione formale, può essere interpretato in, almeno, due modi differenti, uno debole ed uno forte. In entrambe le concezioni esso è, comunque, espressione di una razionalità che possiamo chiamare sussuntiva. Ver também o texto de GUASTINI, Ricardo. Teoria e dogmatica delle fonti. Milano: Giuffré, 1998 - mesmo considerando que sua teoria da argumentação opera mais com a lógica de sentido frágil e particularista (quase cética), porque restringida a ações de densificação material normativa levada a cabo pela atividade judicial na solução de casos concretos, portanto, a seu juízo, não universalizável.

27 Ver o texto de MENGONI, Luiggi. Ermeneutica e Dogmatica Giuridica. Milano: Giuffrè, 2006, p.29 e seguintes. Ainda agrega o autor aqui outras diferenças, seguindo o raciocínio de Alexy, tais como: (1) i principi sono soggetti ad eccezioni implicite, non chiaramente determinate in anticipo (sono norme defettibili), e quindi 
Dal punto di vista di più generali concezioni filosofico-giuridiche, poi, la teoria della distinzione forte può essere utilizzata per sostenere una posizione (cripto-)giusnaturalista, o antipositivista, o neocostituzionalista - posizioni queste che sfruttano la teoria della distinzione forte tra regole e principi per segnalare una falla nel dogma giuspositivistico della separazione tra diritto e morale. Questa è chiaramente l'impostazione di autori come Ronald Dworkin, Robert Alexy, Manuel Atienza, e Gustavo Zagrebelsky. ${ }^{28}$

Mas quais seriam as diretivas do discurso? Para que serviriam? Serviriam para garantir imparcialidade da argumentação no âmbito da interlocução de sujeitos de direito (regras específicas do discurso); tais regras seriam: (a) qualquer um que possa falar poderá tomar parte no discurso; (b) qualquer um pode questionar qualquer afirmação; (c) qualquer um pode introduzir qualquer afirmação no discurso; (d) qualquer um pode expressar atitudes, desejos e necessidades; (e) nenhum interlocutor será proibido de exercer os direitos postos nos itens $\mathbf{a}$ e $\mathbf{b}$, por nenhuma sorte de coerção interna ou externa ao discurso29.

Stanley Paulson sustenta que a matriz jurídica de Alexy deriva de uma articulação de duas dimensões: uma dimensão institucional composta pelas características do Positivismo de Eficácia Social e elaboração da lei consoante o procedimento formal estabelecido; e uma dimensão ideal ou discursiva, composta pela correção, elemento que tomado isoladamente corresponderia a uma abordagem de Direito Natural, sendo que sua idéia seria exatamente a de conciliar ambas as dimensões em uma teoria compreensiva do Direito, através de modelo que leve em consideração aplicação de normas positivadas, legalmente estabelecidas e válidas, e também exige que as mesmas apresentem conteúdos compatíveis à correção ${ }^{30}$.

sono ragioni non conclusive, applicabili solo prima facie, poiché la loro applicazione può essere differita una volta considerati tutti i fattori rilevanti; di contro, le regole sarebbero soggette ad applicazione categorica, tutto-o-niente, una volta verificatesi le circostanze fattuali previste nella fattispecie; (2) i principio sono "mandati di ottimizzazione", cioè prescrivono il perseguimento di un certo obiettivo, valore ecc., nella maggior misura possibile a seconda delle concrete possibilità fattuali e normative.

28 MANIACl, Giorgio. Note sulla teoria del bilanciamento di Robert Alexy. Op. cit., p.06. Por outro lado, uma Teoria Fraca da diferença entre Princípios e Regra, sustentaria que La teoria della distinzione debole si basa sull'osservazione che, a ben vedere, tutte le norme, siano esse regole o principi, sembrano possedere in qualche misura almeno alcune delle caratteristiche sopra indicate. Ciò che differenzia regole e principi, secondo questa posizione, è il grado in cui tali caratteristiche si ritrovano rispettivamente nelle regole e nei principi: così, i principi sarebbero norme più generiche, più aperte ad eccezioni implicite rispetto alle regole, avrebbero una maggiore dimensione di "peso", sarebbero ragioni meno conclusive, e così via. Alguns autores importantes de perfilham nesta perspectiva, dentre os quais: RAZ, Joseph. Legal Principles and the Limits of Law, in "Yale Law Journal", 81, 1972, pp. 823-854; MACCORMICK, Neil. Ragionamento giuridico e teoria del diritto. Op. cit., em especial o capítulo VII; GIANFORMAGGIO. Luciano. Filosofia del diritto e ragionamento giuridico, a cura di E. Diciotti e V. Velluzzi, Giappichelli, Torino, 2008, pp. 173-204.

29 ALEXY, Robert. A argumentação jurídica como discurso racional. Op.cit., p.09. Ver também o texto ALEXY, Robert. A Discourse-Theoretical Conception of Practical Reason. In Ratio Juris 5, (3):231-251, 1992.

30 ALEXY, Robert \& PAULSON, Stanley \& PAULSON, Bonnie. The Argument from Injustice: A Reply to Legal Positivism. London: Oxford, 2010. E com isto escapa Alexy da idéia regulativa do discurso ideal - aqui 
Alexy já teve oportunidade reconhecer isto quando afirmou que a teoria do discurso pertence à classe das teorias procedimentais envolvendo sujeitos localizados no tempo e no espaço ${ }^{31}$. Segundo as teorias procedimentais, a adequação de uma norma ou a verdade de uma proposição depende de se a norma ou a proposição é ou pode ser o resultado de um procedimento determinado.

Tal procedimento, por sua vez, demanda requisitos e caráter específicos para ser devidamente controlado. Dentre estes requisitos, destacam-se: a fixação de determinadas características cognitivas e motivadoras dos indivíduos, passando pela especificação de condições ou circunstâncias sob as quais se argumenta e se decide, até a formulação de regras que determinam como proceder, sendo que as diferenças mais significativas provêm da força dos requisitos exigidos.

Ademais, esta teoria do discurso pressupõe que os seus participantes (seres humanos tais como efetivamente existem), são em princípio capazes de distinguir entre bons e maus fundamentos de proposições substanciais, ou seja, detêm capacidade de discernimento, todavia, é preciso ter em conta que:

Se o pressuposto de que, em princípio, existe uma suficiente capacidade de discernimento - isto é, a faculdade de distinguir entre os bons e os maus fundamentos de proposições substanciais- é introduzida dessa maneira, como uma conexão entre procedimento e adequação, pergunta-se por que tomar por base o procedimento e não simplesmente os bons fundamentos ou as justificativas suficientes. A explicação para isso, pelo menos em questões práticas que concernem essencialmente à interpretação e à conciliação de interesses, é que não há bons fundamentos existentes em si mesmos. O que efetivamente é um bom fundamento só vai se revelar no processo da investigação discursiva. Caso se queira lançar mão dos conceitos de subjetividade e objetividade, pode-se dizer que o resultado do procedimento discursivo não é nem somente subjetivo nem exclusivamente objetivo. Ele é subjetivo na medida em que é condicionado pelas características peculiares dos participantes. Ele é objetivo na medida em que pôde resistir à investigação discursiva efetivada com base em uma suficiente capacidade de discernimento dos participantes. Desta maneira a teoria do discurso evita tanto as falhas das teorias morais subjetivistas ou relativistas, como as falhas das teorias morais objetivistas. 32

\footnotetext{
entendido como o discurso que procura responder a uma questão prática sob as condições de tempo ilimitado, participação ilimitada, completa ausência de constrangimento no processo de produção da perfeita clareza lingüístico-conceitual, capacidade de informação empírica completa, total capacidade e disponibilidade para troca de papéis e total liberdade de preconceitos.

31 ALEXY, Robert. Die Idee einer prozeduralen Theorie der juristischen Argumentation. In Rechtstheorie, caderno 2 (1981), pp.178.

32 ALEXY, Robert. Probleme der Diskurstheorie. In Zeitschrift für philosophische Forschung, Band 43, 1989, pp. 81-93. Tradução de João Maurício Adeodato, Faculdade de Direito do Recife, p. 89.
} 
Já no que tange ao caráter do procedimento, este depende do número de indivíduos e dos tipos de requisitos exigidos. A diferença mais importante aqui diz com o fato de se está ou não prevista, com base no procedimento, a possibilidade de uma mudança nas convicções e nos interesses empíricos e normativos matriciais dos participantes, isto porque a teoria do discurso enquanto modelo de teoria da argumentação é, em contrapartida, caracterizada pela possibilidade de as convicções, assim como os interesses dos indivíduos, modificarem-se por causa de argumentos apresentados ao longo do procedimento.

Em outro trabalho, Alexy vai sustentar, na linha de raciocínio aqui exposta, que os requisitos exigidos pela teoria do discurso podem ser inteiramente formulados através de regras, as quais dizem respeito com prescrições sobre a não-contradição, clareza de linguagem, verdade empírica e sinceridade; a idéia de universalidade, garantindo a todos o direito de participarem do discurso e de serem tratados com igual consideração; a argumentação sobre as conseqüências, ponderação e análise da gênese das convicções normativas 33 .

As críticas que Alexy apresenta à Teoria do Discurso Jurídico são importantes:

Um dos principais problemas da teoria do discurso é seu sistema de regras não oferecer um procedimento finito de operações por meio das quais um agente racional possa sempre chegar a um resultado preciso. Para isso, existem três razões. Em primeiro lugar, as normas do discurso não contêm qualquer definição quanto aos procedimentos de partida. Pontos de partida são as convicções normativas dos participantes e as interpretações dos interesses. Em segundo lugar, as regras do discurso não definem todos os passos a serem tomados na argumentação. Em terceiro lugar, uma série de regras do discurso tem caráter ideal e, portanto, só podem ser realizadas de modo aproximado, ou seja, parcial. Nessa medida, a teoria do discurso não oferece decisões determinadas. 34

Na dicção de Enrico Grosso isto implica ter como pressuposto que tutti $i$ soggetti in gioco (specie i più deboli) debbono avere la possibilità di far sentire la propria voce. II reclutamento dei partecipanti a tali processi dovrebbe quindi prevedere anche sforzi diretti

\footnotetext{
33 ALEXY, Robert. Teoria da Argumentação Jurídica: a teoria do discurso racional como teoria da justificação jurídica. Op.cit., p.187 e seguintes. Em trabalho posterior, Alexy vai alertar para o fato de que: É um mal-entendido pensar que algo já seria verdadeiro segundo a teoria do discurso, pelo simples fato de todos o terem como verdadeiro. Não é o consenso que ela considera decisivo, mas sim a condução do procedimento discursivo. Isto vai ao ponto de se admitir que, até mesmo em caso de dissenso, as opiniões mutuamente incompatíveis podem ser descritas como "adequadas", em um sentido a ser especificado mais à frente, desde que tenham atravessado todo o procedimento discursivo. Por isso é incorreto acusar a teoria do discurso de tomar o consenso como fundamento da adequação ou da verdade. In ALEXY, Robert. Probleme der Diskurstheorie. Op.cit., p.88.
}

34 ALEXY, Robert. Die Idee einer prozeduralen Theorie der juristischen Argumentation. Op.cit., p.10. 
a coinvolgere soggetti marginali che altrimenti non sarebbero presenti per ragioni culturali, sociali e materiali35.

É óbvio que a ausência de igualdade material no âmbito não só do acesso da informação e dos instrumentos de participação, mas também das condições de operar com estes dados (cidadãos que não têm condições cognitivas, intelectuais, de saúde, alimentares, de discernimento para participar efetivamente do debate público e sobre ele manifestar sua vontade autônoma), gera relações interlocutivas coatadas, configuradas por monólogos autoritários e manipuladores.

Aliás, é preciso dizer que uma das bases fundantes do pensamento de Alexy - Habermas - tem plena consciência disto, eis que estas são circunstâncias que caracterizam bem a comunicação coatada, diferentemente do que afirmam alguns de seus interlocutores no sentido de que as chamadas condições ideais de fala configurariam extremismos transcendentais - metafísicos - do autor alemão36. Estas condições ideais de fala dizem respeito às condições subjetivas e objetivas mínimas capazes de levar à emancipada e critica compreensão do mundo da vida e suas relações, viabilizadora de acordos mútuos possíveis; mesmo assim, em face de um amplo consenso de fundo acerca de certezas concernentes ao mundo da vida, não é raro que mesmo garantias frágeis sirvam como base para uma aceitação capaz de criar obrigações relevantes para as conseqüências da ação37. Vai mais longe ainda:

Uma base autônoma na sociedade civil, independente da administração pública e do comércio privado por intermédio do mercado, é considerada uma pré-condição para a práxis da autodeterminação cívica. Essa base resguarda a comunicação política de ser engolida pelo aparato governamental ou assimilada pelas estruturas de mercado. $\mathrm{Na}$

35 GROSSO, Enrico. Cittadinanza e vita democratica dell'Unione tra democrazia rappresentativa e democrazia partecipativa.. In LUCARELLI, Alberto (a cura di). Quaderni della Rassegna di Diritto Pubblico Europeo, vol I. Napoli: Edizioni Scientifiche Italiane, 2008, p.105.

36 Como quer ZIZEK, Slavoy. Enjoy Your Symptom. London: Routledge, 1992. Na mesma direção que Zizek, vai MOUFFE, Chantal. Deliberative Democracy or Agonistic Pluralism? Op.cit., p.37, com seu modelo de Democracia Agonística, afirmando que: the fact that there can never be total emancipation but only partial ones. This means that the democratic society cannot be conceived any more as a society that would have realized the dream of a perfect harmony or transparency. Its democratic character can only be given by the fact that no limited social actor can attribute to herself the representation of the totality and claim in that way to have the "mastery" of the foundation. O problema é que, para evitar de maneira democrática a guerra antropofágica de todos os possuidores da verdade sobre o que é bom para todos, é preciso estratégias de entendimentos civilizatórios, por mais precários e contingenciais que sejam.

37 HABERMAS, Jürgen. Direito e Democracia: entre facticidade e validade. Volume I. Rio de Janeiro: Tempo Brasileiro, 2003, p.346. Alexy concorda com esta posição habermasiana, pois já teve oportunidade de dizer que: Mesmo no caso de um discurso ideal potencialmente infinito não pode ser excluída a possibilidade de efetivação de consenso; também no caso de um discurso ideal potencialmente infinito jamais se pode afirmar que um discurso já obtido é final ou definitivo. ALEXY, Robert. Probleme der Diskurstheorie. Op.cit., p.86. 
concepção republicana, a esfera público-política adquire, juntamente com sua base na sociedade civil, uma importância estratégica. ${ }^{38}$

Daí porque o caráter ideal da teoria do discurso conduz à necessidade de sua incorporação em uma teoria do Estado e do Direito, isto porque, um sistema jurídico que pretenda dar resposta às necessidades de racionalidade prática somente pode começar a existir mediante uma ligação de elementos institucionais ou reais com elementos de tipo ideal e não institucionais39. Para além disto, é preciso ter em conta - lembrando Kant que em um discurso racional nem todos os sistemas jurídicos podem ser justificados, mas apenas os que cumprem as exigências elementares da racionalidade prática, dentre as quais ganha destaque a garantia dos direitos humanos fundamentais e a institucionalização dos procedimentos democráticos e do Estado de Direito. Assim, a teoria do discurso acaba por constituir a base da teoria democrática do Estado Constitucional.

Recentemente, em trabalho publicado nos Estados Unidos da América, Alexy tem ratificado suas posições mais antigas sobre os temas discutidos, sustentado, dentre outras coisas e no âmbito do direito constitucional, que há duas diferentes construções de direitos: a construção por regras e a construção por princípios, sendo que nenhuma delas cumpre, sozinha, à função absoluta e satisfativa de atender a complexidade dos temas que enfrentam, e tampouco representam idéias opostas entre si sobre todas as soluções oriundas da doutrina constitucional. E por que isto? Pelo fato de que questões condizentes a direitos constitucionais não pertencem simplesmente a uma área particular do direito, pois as respostas decorrentes delas têm conseqüências em toda a estrutura do sistema jurídico e mesmo social40.

A lógica que informa o raciocínio do autor aqui é a mesma exposta no clássico livro sobre Teoria dos Direitos Fundamentais ${ }^{41}$, ou seja, distinguindo entre regras e princípios jurídicos, tendo nos primeiros normas que requerem algo de forma definitiva

38 HABERMAS, Jürgen. Três Modelos Normativos de Democracia. In HABERMAS, Jürgen. A Inclusão do Outro: estudos de teoria política. São Paulo: Loyola, 2002, p.277.

39 ALEXY, Robert. A argumentação jurídica como discurso racional. Op. cit., p.11. Adverte o autor que: A teoria discursiva do Direito conduz, como já explicado, para uma necessária institucionalização de um sistema jurídico. Isso implica autoridade do direito positivo. De acordo com os critérios da teoria do discurso, a institucionalização bem sucedida inclui os princípios do Estado democrático constitucional, entre outros, os da democracia, da separação dos poderes e da supremacia do Direito. O princípio da autoridade do direito positivo, estando apoiado por esses outros princípios, exige uma prioridade das razões institucionais frente às razões substanciais. No entanto, isso é apenas uma prioridade prima facie.

40 Estou falando do texto ALEXY, Robert. The Construction of Constitutional Rights. In Law \& Ethics of Human Rights, Volume 4, Issue 1. Article 2. Berkeley: Berkeley Electronic Press, 2010. Nas palavras do autor: Questions pertaining to constitutional rights are not simply questions in a particular area of law. The answers given to such questions have consequences for the structure of the entire legal system. The spectrum extends from the third party or horizontal effect, that is, the bearing of constitutional rights on private law, right up to the relation between the legislature and the practice of constitutional review, behind which the tension between constitutional rights and democracy is found. (p.03).

41 ALEXY, Robert. Teoria de los Derechos Fundamentales. Madrid: Centro de Estúdios Constitucionales, 1990. 
(definitive commands), cuja forma de aplicação é o que chama de subsunção, entendida como: If a rule is valid and applicable, it is definitively required that exactly what it demands be done. If this is done, the rule is complied with; if this is not done, the rule is not complied with ${ }^{42}$.

Por outro lado, os princípios dizem com algo que devem ser realizados na máxima extensão possível, levando em conta as possibilidades fáticas e legais que estejam disponíveis (given the factual and legal possibilities at hand), daí porque se apresentam como mandados de otimização, ou seja, they are characterized by the fact that they can be satisfied to varying degrees, and that the appropriate degree of satisfaction depends not only on what is factually possible but also on what is legally possible $e^{43}$.

Esta forma subsuntiva de aplicação das regras (principalmente constitucionais), todavia, não se afigura tarefa fácil ou de apego irrestrito às dimensões gramaticais da lei escrita, eis que Subsumption, here as elsewhere in the Law, can be rather difficult and may require intermediate steps as well as further arguments of different kinds in order to justify these intermediate steps ${ }^{44}$. Ou seja, não raro a atribuição de sentido que se dá às normas em face do caso concreto pode gerar situações de não adequação ou pertinência, impossibilitando sua aplicação - por isto todos os casos são de complexa solução. Em suas próprias palavras: A clareza de um caso, seja como for, não é algo tão simples assim. Quem afirma que uma decisão é clara, dá a entender que não há argumentos que dêem motivo a dúvidas sérias. No entanto, estes argumentos são sempre concebíveis 45 .

Alexy insiste com a tese de que nestes cenários há que se ter formas controláveis e públicas de procedimentos decisionais envolvendo a aplicação fundamentada do sistema normativo à solução de problemas intersubjetivos ou sociais judicializados. E que formas são estas? Uma delas é o chamado balanceamento de normas.

É o próprio autor que define o balanceamento como a terceira fase do teste de ponderação normativa que propõe à análise e decisão de casos judiciais: It has already

42 ALEXY, Robert. The Construction of Constitutional Rights. Op.cit., p.04.

43 Idem. Adverte ainda o autor que: The determination of the appropriate degree of satisfaction of one principle relative to the requirements of another principle is balancing. Thus, balancing is the specific form of the application of principles...... The debate over the principles theory is, first of all, a debate over weighing or balancing-and, therefore, since balancing is the core of the proportionality test, a debate over proportionality analysis. Tenho consciência dos problemas que tais premissas implicam à efetivação de direitos fundamentais, notadamente no âmbito dos prestacionais-sociais. Grifos meus. Já tratei disto em meu texto LEAL, Rogério Gesta. Condições e possibilidades eficaciais dos Direitos Fundamentais Sociais: os desafios do Poder Judiciário no Brasil. Porto Alegre: Livraria do Advogado, 2009. Mais tarde farei referência aqui também a este problema.

${ }^{44}$ ALEXY, Robert. A theory of legal argumentation: the theory of rational discourse as theory of legal justification. In Ratio Juris,vol. 37. New York: Hammel, 2010, p.30. Os exemplos que o autor dá para tal afirmação são fortes, ao dizer que: Thus, it can be very doubtful whether a certain statement is an expression of one's opinion-protected by the freedom of speech, or whether a certain activity is an exercise of religion, or whether a certain valuable advantage counts as property - protected by the constitution.

45 ALEXY, Robert. Teoria da Argumentação Jurídica: a teoria do discurso racional como teoria da justificação jurídica. Op.cit., p.21. 
been noted that balancing is the subject of the third sub-principle of the principle of proportionality. This is the principle of proportionality in the narrower sense, which concerns optimization relative to the legal possibilities at hand46, lembrando que o autor alemão compreende esta ponderação em três dimensões sucessivas e complementares, a saber: (a) adequação - ou sub-princípio da idoneidade -, estando a exigir que toda a restrição aos direitos (notadamente aos fundamentais) seja idônea para o atendimento de um fim constitucionalmente legítimo, além do que os meios empregados deverem ser instrumentalmente adequados para alcançar o fim almejado; (b) necessidade (ou sub-princípio da indispensabilidade, do meio menos restritivo, do direito à menor desvantagem possível), no sentido de que dentre as várias medidas restritivas de direitos igualmente aptas para atingir o fim perseguido, a Constituição impõe que o legislador opte por aquela menos lesiva para os direitos envolvidos (certa proibição de excesso) ${ }^{47}$; (c) proporcionalidade em sentido estrito, no sentido de que uma restrição aos direitos é constitucional se pode ser justificada pela relevância da satisfação do princípio cuja implementação é buscada por meio da intervenção48.

Este balanceamento por certo que não é mecânico ou de sopesamento subjetivo de importância, validade ou vigência das normas do sistema jurídico, mas envolve juízos de valor na atribuição de sentido da norma ao caso concreto, a partir de parâmetros e diretrizes igualmente normativas, controladas e capazes de serem aferidas publicamente. Para além disto, como lembra Maniaci:

La seconda tesi che sosterrò è che nella Teoria dei diritti fondamentali Alexy, sebbene in modo non sempre sufficientemente chiaro, elabora un modello del bilanciamento tra principi secondo il quale le regole che determinano la precedenza di un principio sull'altro non soltanto sono defettibili, vista l'impossibilità di determinare tutte le proprietà rilevanti, ma sono, e devono sempre interpretarsi, come regole che impongono una relazione di precedenza 'relativa' soltanto ad alcuni tra i casi (generici) in relazione ai quali i due principi possono confliggere, relazione di precedenza che non è necessariamente valida per altri casi. 49

\footnotetext{
46 ALEXY, Robert. The Construction of Constitutional Rights. Op. cit., p. 09.

47 É interessante como Alexy associa este sub-princípio à lógica do Ótimo de Pareto: the subject of the first two sub-principles, the sub-principle of suitability and necessity, is optimization relative to the factual possibilities. In this respect, they are concerned with the question of whether the factual possibilities allow for the avoidance of costs to constitutional rights without bringing about costs contrary to the aims of the legislator. The issue, in other words, is Pareto-optimality. Op.cit., p.10.

48 The basic idea of optimization relative to the legal possibilities at hand can be expressed by a rule that might be called the "Law of Balancing." A statement of this rule runs as follows: "The greater the degree of non-satisfaction of, or detriment to, one principle, the greater must be the importance of satisfying the other". Idem, p.11. Ver também ALEXY, Robert. Teoría de los Derechos Fundamentales. Madrid: Centros de Estudios Constitucionales, 2000, p.112.

49 MANIACI, Giorgio. Note sulla teoria del bilanciamento di Robert Alexy. Op.cit., p.03. Ainda lembra o autor que: In termini guastiniani la regola che determina la precedenza di un principio sull'altro sarebbe una 'gerarchia
} 
No campo específico das regras jurídicas constitucionais, por exemplo, temse algumas particularidades que Alexy no texto refere, envolvendo o que chama do fenômeno da Reserva Legal dos sistemas normativos (statutory reservation), when a constitutional rights provision guarantees, in a first step, constitutional rights such as the right to life and to bodily integrity, and, in a second step, then empowers the legislature by means of a clause such as [t] hese rights can only be interfered with on a statutory basis50.

No caso da Constituição Brasileira de 1988 têm-se algumas situações em que a própria Carta Política estabelece direitos fundamentais e os restringe ao mesmo tempo, ex vi o disposto no art.5०, XVI, ao garantir o direito de reunião, e estabelecendo regras para tanto, cotejado com o disposto no art.136, §1, I, a (Estado de Defesa), e art.139, IV (Estado de Sítio, em que poderá haver restrições a este direito de reunião.

O sistema jurídico precisa conviver com esta instabilidade material que a reserva legal cria, mesmo que aparentemente paradoxal em face das expectativas que se tenham gerado pela aparência de segurança e confiabilidade que ele igualmente deve garantir. O problema por vezes é como lidar com isto, pois, a meu juízo, não é uma ferramenta como a do círculo hermenêutico (Gadamer e alguns de seus sedizentes seguidores), como tal, que vai ajudar muito, pelo simples fato de que ela não diz nada sobre os critérios de afirmação ou rejeição da hipótese de interpretação/aplicação que se poderia usar nestes casos. Essa pergunta só pode ser decidida com base em argumentos. Isso já demonstra que a teoria do círculo hermenêutico não pode substituir uma teoria da argumentação jurídica51. Vai mais longe o autor, e com ele concordo:

Por um lado, para compreender uma norma, é necessário compreender o sistema de normas ao qual ela pertence; de outra sorte, não é possível compreender um sistema de normas sem compreender as normas específicas pelas quais o sistema é constituído. Novamente, encontramos, aqui, apenas a formulação de um problema, mas nenhum critério é oferecido para sua solução. O problema reside na criação de unidade ou de coerência. Essa é a tarefa da argumentação sistêmica. 52

assiologica móbile'.

50 ALEXY, Robert. The Construction of Constitutional Rights. Op.cit., p.05.

51 ALEXY, Robert. A argumentação jurídica como discurso racional. Op.cit., p.04. Já referi anteriormente, com Habermas, que o pensamento crítico dialético capta a necessidade da reflexão que a hermenêutica filosófica gadameriana não leva até as últimas conseqüências, reconhecendo a importância da tradição e da autoridade, porém, problematizando-as a partir do enfrentamento dos seus postulados instituídos, para superá-los no movimento dialético das interlocuções tensas e conflitantes que a comunicação (o mais possível e criticamente - princípio regulativo) não coatada possa desenvolver.

52 Idem. Aduz em seguida Alexy que: A justeza de uma interpretação só pode ser provada quando forem determinadas as razões em seu favor e rejeitados os motivos que a ela se opõem. Portanto, a frase "interpretação é argumentação" torna-se verdade.(p.05). É interessante que este debate inclusive se estende para o significado mesmo de norma jurídica, lembrando aqui GUASTINI, Ricardo. Le fonti del diritto e l'interpretazione. Milano: Giuffrè, 1993, p.32: Si è assunta dunque piena consapevolezza della distinzione concettuale tra la "disposizione", intes a come il testo scritto della legge e la "norma", come significato che, attraverso l'interpretazione, viene attribuito 
As situações que envolvem, por exemplo, a garantia da liberdade religiosa e de crença (art.5, $\mathrm{VI}, \mathrm{CF}$ ) e os efeitos práticos em decorrência de tal direito fundamental, podem apresentar situações em que o balanceamento das possibilidades de sua interpretação/aplicação necessite de cotejamento com outros direitos fundamentais eventualmente em jogo. Estou falando, por exemplo, da possibilidade de pessoas cujas crenças religiosas não lhes permitam desenvolverem certas atividades em determinados dias desejarem ter calendário alternativo à realização de concurso público. Neste ponto já teve oportunidade de dizer o Supremo Tribunal Federal que:

EMENTA: Agravo Regimental em Suspensão de Tutela Antecipada. 2. Pedido de restabelecimento dos efeitos da decisão do Tribunal a quo que possibilitaria a participação de estudantes judeus no Exame Nacional do Ensino Médio (ENEM) em data alternativa ao Shabat 3. Alegação de inobservância ao direito fundamental de liberdade religiosa e ao direito à educação. 4. Medida acautelatória que configura grave lesão à ordem jurídico-administrativa. 5. Em mero juízo de delibação, pode-se afirmar que a designação de data alternativa para a realização dos exames não se revela em sintonia com o principio da isonomia, convolando-se em privilégio para um determinado grupo religioso. 6.Decisão da Presidência, proferida em sede de contracautela, sob a ótica dos riscos que a tutela antecipada é capaz de acarretar à ordem pública 7. Pendência de julgamento das Ações Diretas de Inconstitucionalidade no 391 e no 3.714, nas quais este Corte poderá analisar o tema com maior profundidade. 8. Agravo Regimental conhecido e não provido. 53

Ainda diz o Ministro Relator que o direito fundamental à liberdade religiosa impõe ao Estado o dever de neutralidade diante do fenômeno religioso, revelando-se proscrita toda e qualquer atividade do ente público que favoreça determinada confissão religiosa em detrimento das demais, todavia, o dever de neutralidade por parte do Estado não se confunde com a idéia de indiferença estatal, devendo o Estado, em alguns casos, adotar comportamentos positivos, com a finalidade de afastar barreiras ou sobrecargas que possam impedir ou dificultar determinadas opções em matéria de fé54.

Agora me pergunto, como se daria a discussão envolvendo o direito à crença religiosa - e, portanto, os hábitos e comportamentos decorrentes dela -, em face da necessidade de transplante de sangue, sob risco de vida, a pessoa cuja profissão religiosa o proíba? Aqui Alexy aponta a metodologia do balanceamento como eficiente à decisão judicial: If, however, the rights to freedom, life, and bodily integrity of those concerned

al testo. La norma cioè non è data dal legislatore, né trovata dall'interprete, ma costantemente ricreata nel momento applicativo.

53 Agravo Regimental na Suspensão de Tutela Antecipada n³89, Minas Gerais, Relator(a): Min. GILMAR MENDES (Presidente), Julgamento: 03/12/2009. Órgão Julgador: Tribunal Pleno.

54 Idem, p.10. 
are employed as reasons for imposing limitations, one inevitably confronts the need to balance. In this way, the postulate of systematic interpretation warrants, indeed, requires that one move beyond the scope of the rule model55.

Ato continuo, é interessante verificar como o autor apresenta as objeções que são apresentadas à sua teoria do balanceamento de normas e interesses, a saber:

(1) Objeções Teorético-Normativas, questionando se existem efetivamente normas no sistema jurídico que tenham esta concepção principiológica e regratória dada por Alexy, entendendo ser frágil e equivocada a distinção entre elas 56 .

(2) Objeções Teorético-Argumentativas, estabelecendo uma crítica no plano da baixa racionalidade epistemológica que esta metodologia apresenta, notadamente em face da fragilização de direitos fundamentais 57 .

(3) Objeções Doutrinárias, que questionam se a teoria dos princípios em que está fundada a metodologia do balanceamento não estaria, em verdade, enfraquecendo todo o sistema normativo, uma vez que estabelece hierarquias e pesos distintos a normas jurídicas de mesmo rango 58 .

(4) Objeções Institucionais, no sentido de que o reconhecimento de excessiva força aos princípios constitucionais poderia criar uma espécie de sobre-constitucionalização do sistema jurídico, acessível somente a poucos iniciados, substituindo com isto o modelo de Estado Parlamentar Legislativo por uma espécie de Estado Constitucional Adjudicativo59.

(5) Objeções Teorético-Intepretativas, que questionam se e como a construção constitucional principiológica pode estabelecer, de forma universal, interpretações corretas do catálogo de direitos constitucionais estabelecido enquanto direito positivo60.

\footnotetext{
55 ALEXY, Robert. The Construction of Constitutional Rights. Op.cit., p.06.

56 Cita o autor aqui como referência os textos de POSCHER, Ralf. Einsichten, Irrtümer und Selbstmißverständnisse der Prinzipientheorie. In Die Prinzipientheorie der Grundrechte: studien zur grundrechtstheorie Robert Alexys. 59, 65, 70 (Jan-R. Sieckmann ed., 2007); e o de KLEMENT, Jan Henrik. Vom Nutzen einer Theorie, die alles erklärt, 63. Juristenzeitung 756, 760 (2008).

57 Neste passo o autor aponta os textos de HABERMAS, Jürgen. Between Facts and Norms: contributions to a discourse theory of law and democracy. William Rehg trans., Polity Press, 1996; e SCHLINK, Bernhard. Der Grundsatz der Verhältnismäßigkeit, in Festschrift 50 Jahre Bundesverfassungsgericht 445, 460 (Peter Badura \& Horst Dreier eds., 2001).

58 Cita aqui o autor o mesmo texto de HABERMAS, Jürgen. Between Facts and Norms: contributions to a discourse theory of law and democracy. Op.cit., dizendo que: See HABERMAS, supra note 12, at 25859 (maintaining that conceptions of rights as principles might result in the collapse of rights that are properly understood, i.e., rights act as a "fire wall.").

59 Refere o autor aqui o texto de BÖCKENFÖRDE, Ernst-Wolfgang. Staat, Verfassung, Demokratie 190 (1991).

60 Cita o autor aqui o trabalho de JESTAEDT, Matthias. Die Abwägungslehre - ihre Stärken und ihre Schwächen. In Staat im Wort: Festschrift für Josef Isensee 253, 260, 262-63, 275 (Otto Depenheuer, Markus Heintzen, Matthias Jestaedt, \& Peter Axer eds., 2007).
} 
(6) Objeções Teorético-Validativas, no sentido de que esta teoria dos princípios estaria por arriscar o status de superioridade da Constituição e a sujeição a ela dos Poderes Estatais instituídos, colapsando a estrutura hierárquica do sistema jurídico ${ }^{61}$.

(7) Objeções Teorético-Científicas, sustentando que a teoria dos princípios faz declarações cujas razões de fundamentação e justificação são demasiadamente abstratas, servindo minimamente para explicar decisões tomadas, mas sem estabelecer diretrizes para tomada de decisões no futuro62.

De todas estas considerações, Alexy destaca as objeções teorético-argumentativas, eis que seu fundamento se centra na idéia de que se o balanceamento de normas em face dos interesses envolvidos é naturalmente irracional - porque refoge da lógica do sistema normativo -, efetivamente dever-se-ia rejeitá-lo, todavia isto não é assim, porque se esta metodologia se apresenta como irracional, não faria sentido usá -la como critério de admissibilidade dos limites dos direitos constitucionais. Habermas e Schlink é que têm insistido com esta tese, sob o argumento, o primeiro, de que se afigura demasiadamente irracional a pretensão ponderativa/balanceamento de Alexy, por falta de controle dos critérios desta ação, ensejando a possibilidade de arbitrários costumes não refletidos na aplicação do chamado teste da proporcionalidade; o segundo, sob o argumento de que isto geraria arbitrários subjetivismos63.

Alexy responde a estas assertivas de Habermas e Schlink, sustentando que a lei do balanceamento (referida mais acima) mostra que pode não funcionar em três situações: (a) quando se afiguram níveis de não satisfação, ou de detrimento, dos princípios jurídicos envolvidos; (b) quando igualmente não se operam a tensão entre princípios jurídicos; (c) quando não se afigura importante a solução da tensão entre princípios. Conclui o autor: If it were not possible to make rational judgments about, first, intensity of interference, second, degrees of importance, and, third, their relationship to each other, the objections raised by Habermas and Schlink would be justified 64 .

A idéia de fundo que está aqui é a de que se afigura mais do que possível, mas recomendado, no âmbito da ponderação e do balenceamento de normas em face do caso concreto, elaborar certa ordem hierárquica conjuntural entre os princípios que se encontram em tensão na casuística, tutelando assim um valor importante ao sistema jurídico que é a certeza do direito, entretanto, ele não é o único que demanda

61 Estes seriam argumentos também utilizados por Matthias Jestaedt e Jan Henrik Klement, anteriormente citados.

62 Cita o autor aqui o texto de Ralf Poscher, referido anteriormente.

63 Alexy está fazendo referência aqui ao trabalho de HABERMAS, Jürgen. Between Facts and Norms: contributions to a discourse theory of law and democracy. Op.cit., e de SCHLINK, Bernhard. Freiheit durch Eingriffsabwehr-Rekonstruktion der klassischen Grundrechtsfunktion,11 EUROPÄISCHE GRUNDRECHTE-ZEITSCHRIFT (EUGRZ) 457, 462 (1984): In the test of proportionality in the narrower sense, it is only the subjectivity of the tester that can, in the end, be effective... The operations of evaluation and balancing required by the proportionality test in the narrower sense can be achieved ... in the end, only in a decisionistic manner.

64 ALEXY, Robert. The Construction of Constitutional Rights. Op.cit., p.10. 
realização, pois ao seu lado está o valor de caráter pragmático relativo à eficiência social da prestação jurídica, igualmente importante e cuja realização pode eventualmente mitigar a realização do ideal de completude do ordenamento jurídico.

A questão, pois, que se coloca, é se esta metodologia de abordagem da norma jurídica, em face dos casos concretos e dos procedimentos que se fomentam à decisão judicial, apresentam ou não níveis de racionalidade pública e controláveis pela via da argumentação/comunicação jurídica.

Alexy responde positivamente, dando um exemplo ocorrido na Corte Constitucional Alemã - e que serve para o Brasil-, quando tratou do tema envolvendo a obrigatoriedade das indústrias produtoras de tabaco colocarem em seus produtos fumígeros advertências sobre os riscos à saúde que estes representam. Concluiu Alexy que tal obrigação poderia ser aferida em face da ponderação de interesses existentes na espécie, utilizando a lei do balenceamento, chegando à conclusão de que, primeiro, não haveria qualquer conflito intransponível entre a regulação estatal no âmbito da produção e venda daqueles produtos e a liberdade de profissão, atividade industrial ou comercial; segundo, sequer existiria excessiva intervenção pública na ordem econômica, haja vista a proteção de um bem jurídico - vida/saúde - que tem maior peso e importância do que outro bem jurídico tutelado pela mesma Constituição, que é a liberdade de produção e comércio de bens lícitos.

Veja-se que, no Brasil, esta situação está muito bem retratada pelos termos da Lei n`9.294/1996, que versa sobre as restrições ao uso e à propaganda de produtos fumígeros, bebidas alcoólicas, medicamentos, terapias e defensivos agrícolas, nos termos do $§ 4^{\circ}$, do art. 220, da Constituição Federal.

A referida lei federal, em seu art.2 já provocou sério impacto na indústria do fumo e mesmo dos fumantes, uma vez que vedou o uso de cigarros, cigarrilhas, charutos, cachimbos ou de qualquer outro produto fumígero, derivado ou não do tabaco, em recinto coletivo, privado ou público, salvo em área destinada exclusivamente a esse fim, devidamente isolada e com arejamento conveniente65.

A partir do cotejamento desta legislação têm surgido algumas teses no país sobre um possível direito fundamental de (não) fumar, manifestado no âmbito das liberdades reais, autorizando o Estado a intervir no domínio econômico para restringir os efeitos da publicidade de produtos com tais características sobre os potenciais consumidores. 66

De outro lado, a indústria do fumo tem sustentado que o ato de fumar representa um mero hábito e, como tal, advém incondicionalmente de uma opção aberta do

65 Estendendo tal vedação, a recintos tais como: repartições públicas, os hospitais e postos de saúde, as salas de aula, as bibliotecas, os recintos de trabalho coletivo e as salas de teatro e cinema, aeronaves e veículos de transporte coletivo.

66 OLIVEIRA, Amanda Flávio de. Direito de (não) fumar: uma abordagem humanista. Rio de Janeiro: Renovar, 2008, p. 108. 
próprio fumante, caracterizando-se como ação voluntária. Em face disto, os potenciais e mesmo reais efeitos acarretados àqueles que assim decidiram fumar, jamais poderiam ser impingidos às fornecedoras de cigarros, mas exclusivamente ao próprio consumidor de tabaco, eis que, se ele é vítima de enfermidades oriundas do consumo de fumígenos, tal responsabilidade lhe cabe exclusivamente ${ }^{67}$.

O Tribunal de Justiça do Rio de Janeiro, julgando esta matéria, chegou a afirmar que antes da Constituição Federal de 1988, não havia norma legal sobre o fumo, tema encartado no seu art.220, da nova carta política, remetendo a regulamentação para lei ordinária, que só veio a lume em 1996 (Lei n9.294). De outro lado, sustentou esta Corte que de longa data são conhecidos os efeitos negativos do hábito de fumar, socialmente aceito e incentivado. De qualquer sorte, a partir destes novos cenários, os fabricantes passaram a divulgar alertas destacando os perigos à saúde, e a propaganda negativa se tornou mais intensa a partir das regras genéricas do código de defesa do consumidor, intensificando-se após a lei específica.

Aduziu o Acórdão que a industrialização, comercialização e propaganda do tabaco são atividades lícitas e regulamentadas, enquanto que fumar, e manter-se fumante, é escolha pessoal, correndo o interessado os riscos, posto que insistentemente alertado por frenética e permanente campanha contrária. Com base nestes fundamentos, entendeu por bem aquele Tribunal conhecer da culpa exclusiva do consumidor tabagista pelos eventuais malefícios experimentados, tendo, no caso, inocorrido a comprovação efetiva do nexo causal, assim como de utilização exclusiva dos produtos da fabricante do cigarro68.

Conforme Delfino, o livre arbítrio dos consumidores de tabaco nunca esteve de posse do uso razoável de informações e discernimento suficiente sobre todas as variáveis que envolvem a presença do tabaco no organismo humano, exatamente porque as indústrias do ramo sempre ousaram em apologias cinematográficas sobre seus produtos, vinculando-os a situações alheias as suas verdadeiras características. Em outras palavras, o cigarro era ligado ao bem-estar, ao sucesso profissional, à saúde, à sexualidade, à sensualidade, ao prazer, ao requinte, aos esportes, etc., contratando a indústria do tabaco atores e diretores de cinema para que os seus produtos fossem

\footnotetext{
67 Ver a decisão da $5^{\text {a }}$ Câmara Cível, do Tribunal de Justiça do Estado do Rio Grande do Sul, nos autos da Apelação Cível n. ${ }^{\circ}$ 70017634486, tendo por relator o Desembargador Paulo Sérgio Scarparo, em que esta matéria é amplamente discutida. Mas há posições na casuística dando apoio a tese das indústrias do tabaco: Improcedente a ação de indenização movida por doente de câncer na laringe contra fabricante de cigarros, se o nexo causal entre a doença e o tabagismo, apesar do truísmo de que o cigarro provoca tumores malignos, não resta demonstrado, e inexiste prova do consumo exclusivo dos produtos da fabricante. Ressalta-se ainda que o tabagismo não foi imposto ao autor, que aderiu espontaneamente ao vício, não cabendo a alegação de que as advertências quanto aos seus malefícios somente passaram a ser feitas recentemente, porquanto os prejuízos que o cigarro pode causar são sensitivos, quando não intuitivos. TJSP - $4^{\text {a }}$ C. Dir. Privado - Ap. 110.454-4/3-00 - Rel. Narciso Orlandi - j. 22.02.2001 - RT 789/220.

68 Acórdão n 2005.001.40350 - 4a C.Cív. - Rel. Des. Mário dos Santos Paulo - DJRJ 20.07.2006.
} 
retratados, sempre de forma positiva; financiou esportistas para se deixarem mostrar usando tabaco, com a intenção de garantir imagem socialmente aceitável sobre tais hábitos; contratou cientistas e empresas de relações públicas para combater pesquisas que vinculavam o tabagismo a diversas doenças ${ }^{69}$.

Rosemberg demonstra em pesquisas sobre a matéria que uma vez instalada a dependência do tabaco, e faltando o aporte de nicotina nos centros nervosos, surgem quadros clínicos de sintomas desagradáveis, denominado "síndrome de abstinência" -, caracterizado por um forte desejo de fumar, ansiedade, inquietação, irritabilidade, distúrbios do sono, dificuldade de concentração, além de outros sintomas, variando tudo isto em face do grau da dependência70.

Por parte da doutrina especializada, há quem defenda que para responsabilizar pelos males do fumo ter-se-ia também que fazer o mesmo com relação às bebidas alcoólicas, os dietéticos, os adoçantes, os produtos alimentícios transgênicos, os defensivos para lavoura (defensivos agrícolas) que contaminam os alimentos, todos com suspeita fundada de ter atributos cancerígenos se ingeridos durante largo tempo e, inclusive, alguns medicamentos71.

A matéria é tão polêmica e diversificada em termos de entendimento, que há notícias que nos Estados Unidos da América as primeiras demandas contra as indústrias de cigarros surgiram em 1954, sendo que até o ano de 1992 foram abertos 813 processos contra essas empresas; dos 23 que chegaram a julgamento, só dois deles foram favoráveis, em primeira instância, aos fumantes e, ainda assim, acabaram reformados nos Tribunais Superiores 72 .

Em pesquisa feita por Gabriela Invernizzi, no Brasil foram ajuizadas, até 2007, 508 ações indenizatórias dessa natureza contra a empresa Souza Cruz. Nessas ações, foram proferidas 298 decisões rejeitando os pedidos de indenização, havendo 12 decisões pendentes de recurso, em que os fumantes ou suas famílias saíram

69 DELFINO, Lúcio. Jurisprudência e o fumo: Uma guinada em prol dos interesses do fumante. In http://www. adital.com.br/site/noticia.asp?lang=PT\&cod=29646, acessado em 12/02/2009. Alerta o autor para o fato de que, além de todas as variáveis referidas, a liberdade de opção do fumante também resta prejudicada depois que ele se torna dependente, sendo que a medicina concebe o tabagismo como sendo uma doença-crônica, e a própria Organização Mundial de Saúde, desde 1992, cataloga o tabagismo na Classificação Internacional de Doenças - Capítulo F12.2, síndrome da tabaco-dependência. Por sua vez, a Associação Americana de Psiquiatria vê a nicotino-dependência como uma desordem mental pelo uso de substância psicoativa.

70 ROSEMBERG, José. Nicotina. Droga universal. São Paulo: SES/CVE, 2003, p.28. A revista Veja publicou pesquisa dando conta de que, no Brasil, a dependência do tabaco está associada a $90 \%$ dos casos de câncer de pulmão, $85 \%$ dos óbitos por enfisema pulmonar, $40 \%$ dos derrames cerebrais e $25 \%$ dos infartos fatais. Reportagem de Karina Pastore e Anna Paula Buchalla. A Marca da morte nos cigarros. Revista VEJA, Edição n¹.735 (2002). Disponível no site http://www.veja.com.br/.

71 STOCO, Rui. Tratado de Responsabilidade Civil. São Paulo: Revista dos Tribunais, 2007, p.793.

72 Matéria publicada intitulada O Cigarro, no Publifolha, São Paulo, 2001, p. 59. 
vitoriosos. As 199 decisões definitivas já proferidas pelo Judiciário afastaram as pretensões indenizatórias73.

Em termos normativos, a publicidade de tabaco, embora materialmente esteja na mesma posição da de bebidas, goza de certa proteção constitucional. Pode ser limitada - mesmo em profundidade, com vedação de utilização de certos veículos, como a televisão, por exemplo - mas não totalmente proibida, ex vi, o já referido art. 220 , $§ 4^{\circ}$, da Constituição Federal.

O mesmo entendimento se extrai da regulamentação trazida pela Lei n9.294/96, em especial no seu art. $3^{\circ}$, e $\$ 1^{\circ}$, quando assevera que a propaganda comercial dos produtos tabagistas (dentre outros sobre os quais a lei versa) só poderá ser efetuada através de pôsteres, painéis e cartazes, na parte interna dos locais de venda (redação dada pela Lei no 10.167, de 27.12.2000), observados os seguintes princípios: (a) não sugerir o consumo exagerado ou irresponsável, nem a indução ao bem-estar ou saúde, ou fazer associação a celebrações cívicas ou religiosas; (b) não induzir as pessoas ao consumo, atribuindo aos produtos propriedades calmantes ou estimulantes, que reduzam a fadiga ou a tensão, ou qualquer efeito similar; (c) não associar idéias ou imagens de maior êxito na sexualidade das pessoas, insinuando o aumento de virilidade ou feminilidade de pessoas fumantes; (d) não associar o uso do produto à prática de atividades esportivas, olímpicas ou não, nem sugerir ou induzir seu consumo em locais ou situações perigosas, abusivas ou ilegais (redação dada pela Lei n 10.167, de 27.12.2000); (e) não empregar imperativos que induzam diretamente ao consumo; (f) não incluir a participação de crianças ou adolescentes (redação dada pela Lei no 10.167, de 27.12.2000).

Veja-se que o universo de possibilidades de controles de caráter subjetivo que se criou para coibir a violação dos ditames legais atinentes à publicidade e propaganda do tabaco, estará submetido à hermenêutica e aplicação judicial - dentre outros, exigindo do Judiciário a ponderação de todos os interesses envolvidos na espécie, sob pena de inviabilizar de vez este segmento de mercado, que emprega milhares de trabaIhadores brasileiros e é responsável por uma fatia importante de circulação da riqueza.

Isto se revela tão importante porque a Lei sob comento ainda agudizou mais esta atividade produtiva, ao determinar, em seu art.3-A, que é vedado, no que tange aos produtos fumígenos (dentre outros): (a) a venda por via postal; (b) a distribuição de qualquer tipo de amostra ou brinde; (c) a propaganda por meio eletrônico, inclusive internet; (d) a realização de visita promocional ou distribuição gratuita em estabelecimento de ensino ou local público; (e) o patrocínio de atividade cultural ou esportiva; (f) a propaganda fixa ou móvel em estádio, pista, palco ou local similar; (g) a propaganda indireta contratada, também denominada merchandising, nos programas produzidos

73 INVERNIZZI, Gabriela. Substância nociva - Souza Cruz é condenada a indenizar família de fumante. Revista Consultor Jurídico, 2007. In http://www.conjur.com.br/. 
no país após a publicação desta Lei, em qualquer horário; (h) a comercialização em estabelecimento de ensino, em estabelecimento de saúde e em órgãos ou entidades da Administração Pública; (i) a venda a menores de dezoito anos ${ }^{74}$.

\section{CONSIDERAÇÕES FINAIS}

Pode-se ver, a partir destes casos, que o problema da definição de qual norma tem mais peso não reclama uma resposta universal fechada, mas envolve sempre conjunções pragmáticas especiais. Como adverte Schauer:

But because not all legal principles have the same weight, and because the weights that principles do have are typically specified either vaguely or not at all, and finally because the prescriptions of multiple principles can collide in the circumstances of particular application, there remains the important question of how to determine which principle shall prevail in such cases of conflicting principles. 75

O trabalho de Alexy mostra com evidência incisiva que a estrutura do argumento da proporcionalidade faz com que seja menor a instabilidade dos sentidos aplicativos das normas do que um balanceamento aberto por parte dos decisores, no qual estes estão liberados não somente para decidir sobre quais os fatores são relevantes no processo de tomada de decisão, mas também e fundamentalmente sobre qual o peso que cada um destes fatores deve ter.

É claro que Alexy sabe que a chamada escala triádica (triadic scale) de interferência da decisão judicial no âmbito das relações sociais- fraca, moderada e sériea (light, moderate, and serious) 76 - não é suficiente para dar conta da complexidade que sempre representa o processo de interpretação/aplicação de sistemas normativos, em especial

\footnotetext{
74 Veja-se que o art.9º da Lei, determina a aplicação ao infrator desta Lei, sem prejuízo de outras penalidades previstas na legislação em vigor, especialmente no Código de Defesa do Consumidor e na Legislação de Telecomunicações, as seguintes sanções: I- advertência; II - suspensão, no veículo de divulgação da publicidade, de qualquer outra propaganda do produto, por prazo de até trinta dias; III - obrigatoriedade de veiculação de retificação ou esclarecimento para compensar propaganda distorcida ou de má-fé; IV - apreensão do produto; $\mathrm{V}$ - multa, de $\mathrm{R} \$ \mathbf{5 . 0 0 0 , 0 0}$ (cinco mil reais) a $\mathrm{R} \$ \mathbf{1 0 0 . 0 0 0 , 0 0}$ (cem mil reais), aplicada conforme a capacidade econômica do infrator; $\mathrm{VI}$ - suspensão da programação da emissora de rádio e televisão, pelo tempo de dez minutos, por cada minuto ou fração de duração da propaganda transmitida em desacordo com esta Lei, observando-se o mesmo horário; VII - no caso de violação do disposto no inciso IX do artigo 3oA, as sanções previstas na Lei no 6.437, de 20 de agosto de 1977, sem prejuízo do disposto no art. 243 da Lei no 8.069, de 13 de julho de 1990. $\S 1^{\circ}$ As sanções previstas neste artigo poderão ser aplicadas gradativamente e, na reincidência, cumulativamente, de acordo com as especificidades do infrator. $\S 2^{\circ}$ Em qualquer caso, a peça publicitária fica definitivamente vetada.

75 SCHAUER, Frederick. Balancing, Subsumption, and the Constraining Role of Legal Text. In Law \& Ethics of Human Rights Review, vol. 4, Issue 1. Berkeley: Berkeley Electronic Press, 2010, p.04, in http://www.bepress. com/lehr/vol4/iss1/art3, acessado em 09/12/2010. Ou seja: A crucial issue for legal decisionmaking is thus the determination of which of two (or more) discordant principles should be deemed to have the greater weight in a particular situation in which multiple principles are each applicable to the same decision.
}

76 ALEXY, Robert. The Construction of Constitutional Rights. Op.cit., p.12. 
quando se tem de atribuir pesos distintos a normas da mesma estatura constitucional, mas tão somente que é possível usá-la como inferência sistêmica implícita no balanceamento destas normas, a qual, por sua vez, está intrinsecamente conectada com o conceito de correção.

No caso da subsunção de regras jurídicas, explica o autor que aquela inferência sistêmica pode ser expressa pelo esquema dedutivo, chamado justificação interna, construída com o auxílio de proposições, predicados e lógica deôntica integrada no âmbito da Teoria do Discurso Legal e representada pela seguinte fórmula: $W i j=l i / l j$.

Nesta fórmula, o Wij, significa o peso $(W)$ da intensidade da interferência demandada pelas circunstâncias dos direitos aplicados ao caso concreto (i), em face do peso da importância concreta de satisfação dos direitos envolvidos neste caso. Tal medida se consegue através da equação entre a adequação, necessidade e proporcionalidade da infração a determinado princípio (li) e outro que se lhe opõe, no caso concreto (lj). É óbvio, adverte o autor, que: Balancing would be possible once one had a scale with two values, say, light and serious. Balancing is impossible only if everything has the same value ${ }^{77}$.

O que se tem de ter em mente, a partir do referido, é que, por mais que a norma constitucional estabeleça catálogos de direitos e garantias constitucionais referidas como auto-aplicáveis, e disto não se tem dúvidas, o fenômeno de efetivação concretizante destes sempre contará com graus/medidas passíveis de mensuração, e estas, definitivamente, não estão dadas pela Carta Política, demandando do intérprete/aplicador atribuição de sentido racional e material às suas reivindicações, caso por caso (que inclusive pode tratar de interesse, coletivo, difuso ou individual homogêneo), levando em conta o universo de variáveis que convergem a ele, daí porque Schauer insistir na tese de que:

When critics like Habermas accuse the balancing process of being irrational, however, it appears that what they mean is "unconstrained." It is not as if we normally think of other open-ended decision-making approaches as irrational just because they involve some likelihood of variability. A pure but sophisticated act utilitarianism, for example, may impose too many demands on decision-makers, and may involve widely divergent evaluations of the relative utilities involved, but it is hard to see it as irrational. 78

De qualquer sorte, sempre, The rationality of an inferential structure essentially depends on the question of whether it connects premises that, again, can be justified. Mas justificadas estas premissas a partir de que razões e fundamentos válidos? É Alexy que

77 Idem. Para além disto, adverte Alexy que: the justifiability of statements about intensities is a condition of the rationality of balancing. This implies that graduation in the province of constitutional rights can work only with relatively crude scales. Idem, p.13.

78 SCHAUER, Frederick. Balancing, Subsumption, and the Constraining Role of Legal Text. Op.cit., p.07. 
responde: The commensurability of the assessments on both sides of the balance is granted if the discourse is conducted on the basis of a common point of view: the point of view of the constitution 79 .

Desta forma, uma teoria do discurso jurídico que tem a intenção de satisfazer a pretensão à legitimidade da ordem jurídica, há de dar uma resposta à questão acerca de como decisões jurídicas sucedem vinculadas a decisões institucionais precedentes e como podem ser fundamentadas racionalmente 80 .

Fala Alexy, por certo, da vinculação que decisões jurídicas devem ter com outras - institucionais/parlamentares/constitucionais - que servem de demarcação originária à legitimação democrática da ação judicial81. A necessária fundamentação que se exige pela via do discurso jurídico igualmente está demarcada pelos significados e sentidos encetados pelo sistema normativo vigente, que a despeito de em constante mutação, conta com referências, procedimentos e instâncias deliberativas regulares que precisam ser observadas sob pena de dar-se vezo a imposições autoritárias, veiculadas pela assertiva de que La norma è dunque la volontà della legge come pensata da colui che in concreto decide, influenzato dal contesto sociale e giuridico in cui si trova ad operare 82.

E isto ocorre por uma razão muito simples, a saber, pelo fato de que uma teoria coerencial do direito não pode resolver sozinha o problema da aplicação racional do direito. Assim como regras não podem se aplicar a elas mesmas, um sistema não pode produzir ele próprio a resposta correta. Para tanto, são necessários pessoas e procedimentos 83 . Todavia, estas pessoas e procedimentos precisam, por sua vez, estar ancorados em

79 E neste ponto Alexy é muito claro, pois aduz que: Calculable measurements by way of a continuum of points between 0 and 1 cannot have any application. Idem, p.14. Vai na mesma direção o questionamento de TARELLO, Giovanni. Interpretazione della legge. Roma: Giuffrè, 2010, p.61: La questione è dunque comprendere se il ragionamento dell'interprete sia razionale o se piuttosto si determini secondo scelte legate all'opportunità del caso. La sentenza esprime una scelta politica del giudice? La decisione dipende da un sistema di norme predefinito o è soluzione di giustizia individuata in base ai pregiudizi dei soggetti chiamati a decidere?

80 ALEXY, Robert. Os Direitos Fundamentais e a Democracia no Paradigma Procedimental do Direito de Jürgen Habermas. In FRANKENBERG, Günter \& MOREIRA, Luiz. Jürgen Habermas: 80 anos. Rio de Janeiro: Lúmen Júris, 2009 , p.121.

81 Esta preocupação é também institucionalista (além de procedimental), na medida em que reconhece a outros espaços institucionais iguais competências à deliberação pública sobre aspectos normativos da sociedade civil. Lembro-me das reflexões de GRIFFIN, Stephen. American Constitutionalism: from theory to politics. Princeton: Princeton University Press, 1996, ao sustentar que o Judiciário não tem supremacia exclusiva no processo de interpretação constitucional, uma vez que todos os órgãos constitucionais são responsáveis pela efetivação e interpretação do sistema jurídico (notadamente o constitucional).

82 ANDRONICO, Alberto. Ermeneutica e diritto da Wilhelm Dilthey ed Emilio Betti. In Spicchi di Novecento, a cura di Bruno Montanari. Roma: Giappichelli, 2008, p.49. Refere ainda o autor: Posto dunque che il ragionamento che viene seguito per l'applicazione del diritto non è riconducibile alla sola logica formale, ma è scelta da parte del giudice di una tra le varie soluzioni possibili, posto ancora che il diritto non è l'insieme delle norme date dal sovrano, né l'insieme delle decisioni dei tribunali, ma ordine normativo sempre nell'atto di positivizzarsi, la questione che si pone è quella di individuare il reale fondamento della decisione del giudice.

83 Idem. 
sistemas normativos que possuem caráter fundamentalmente deontológico, regulando o contexto vital dos cidadãos de uma comunidade jurídica concreta.

Daí a conclusão de Alexy - diferente de Habermas ${ }^{84}$-, no sentido de que este caráter deontológico do sistema normativo (princípios e regras jurídicas) não implica absolutos, podendo ser compreendido como constituído, dentre outras coisas, por mandados de otimização85, utilizando na ponderação e balanceamento dos princípios em face de casos concretos relações de precedência condicionada que vão indicar as condições na presença das quais um princípio prevalecerá sobre o outro, ou seja, le condizioni in presenza delle quali un principio precede l'altro costituiscono il presupposto di fatto di una regola che esprime la conseguenza giuridica del principio prevalente 86.

Isto também se aplica às regras do discurso jurídico, eis que algumas delas podem apenas ser ou não cumpridas; em outras, ao contrário, devido a seu caráter ideal, só é possível um cumprimento aproximativo. Nestas o cumprimento é uma questão de grau. Assim, surge o problema da relatividade quanto ao grau de cumprimento ${ }^{87}$. Neste sentido é a correta advertência de Schauer:

In making his argument, Alexy maintains, correctly, that both proportionality and balancing arguments have premises, and he maintains as well that in order to identify the premises "all kinds of arguments admissible in legal discourse may be adduced." He thus structures his argument around the claim that once we have identified legally admissible premises, the argumentative forms of balancing and subsumption share more in common than is commonly supposed, especially by balancing's most strident opponents. But in structuring his argument in this way, Alexy at the very least allows and may even

\footnotetext{
84 Habermas entende, aqui, que conceber os princípios informativos do sistema normativo como mandados de otimização permitiria análises envolvendo custos e vantagens, e isto, sob o prisma normativo, levaria a uma restringibilidade dos bens que protege em face de outros bens, mesmo que coletivos. Em outras palavras: Uma jurisprudência orientada por princípios precisa definir qual pretensão e qual ação deve ser exigida num determinado conflito - e não arbitrar sobre o equilíbrio de bens ou sobre o relacionamento entre valores. HABERMAS, Jürgen. Direito e Democracia: entre faticidade e validade. Vol. I. Op. cit., p.323.

85 Habermas é explícito ao defender que: Princípios e regras não têm estrutura teleológica. Eles não podem ser entendidos como preceitos de otimização - conforme é sugerido pela "ponderação de bens" nas demais doutrinas metodológicas -, porque isso suprimiria seu sentido de validade deontológica. Idem, p.258. Argúi o autor que: No desenrolar dos casos, estabelece-se entre os princípios uma ordem transitiva, sem que isso arranhe sua validade, sem explicar pragmaticamente, no entanto, o que entende por ordem transitiva, até porque, no ponto, parece concordar com Dworkin em relação à tese de que: no conflito entre princípios, não se faz necessária uma decisão do tipo "tudo ou nada". É certo que um determinado princípio goza de primazia, porém não a ponto de anular a validade dos princípios que cedem o lugar. Um princípio passa à frente do outro, conforme o caso a ser decidido. (p.259).

86 CELANO, Bernardo. Dialettica della giustificazione pratica. Torino: Giappichelli, 2008, p.51.

87 ALEXY, Robert. Probleme der Diskurstheorie. Op.cit., p.91. Lembro que, ao lado destas questões, há ainda o que Alexy chama de condições limitadoras do discurso jurídico, a saber: (a) o seu caráter de ligação intrínseca à lei; (b) o vínculo que estabelece com os precedentes judiciais (em especial no sistema comunitário); (c) a relação que mantém com a dogmática jurídica (mais crítica ou conformativa); (d) sua sujeição às limitações impostas pelas regras processuais. In ALEXY, Robert. Teoria da Argumentação Jurídica: a teoria do discurso racional como teoria da justificação jurídica. Op. cit., p.27.
} 
encourage the belief that the legally admissible premises of a subsumption argument are similar to the legally admissible premises of a balancing argument. It is this claim of similarity, this quasi-conflation of the two forms of argument that may well ignore a central feature of law itself - its pervasive even if not necessary textuality, and the pervasive formality of law that is the handmaiden of its textuality. 88

O autor alemão está discutindo, no ponto, a importância do conceito de adequação da interpretação/aplicação do sistema jurídico, outorgando a esta idéia função regulativa de tais ações, razão pela qual não pressuporia a decisão judicial, sempre, a existência de uma resposta adequada para cada questão prática, bastando apenas encontrá-la, mas ao contrário, tal desiderato assume o caráter de um objetivo a ser almejado, em que os participantes de um discurso prático, independentemente da questão de se existe uma única resposta adequada, têm de defender a pretensão de que sua resposta é a única adequada, se querem que suas afirmações e fundamentações façam sentido89.

O problema é que esta pretensão dos participantes, por sua vez, não nasce do nada, haja vista que todo discurso tem de ter um ponto de partida, e este ponto de partida está nas convicções normativas existentes dos participantes. Por isto,

O procedimento do discurso nada mais é do que um processo de investigação dessas convicções. Aí, toda convicção normativamente relevante é candidata a uma modificação baseada em argumentação racional. Nesta restrição à estruturação racional da argumentação está uma vantagem importante da teoria do discurso. Uma teoria que tente determinar o processo de argumentação ou de decisão, não apenas através de sua estruturação racional, mas, digamos, através da prescrição de determinados conteúdos como premissas de partida, tem de se haver não somente com objeções às premissas de partida escolhidas pelos teóricos individualmente - e é geralmente mais difícil responder a essas do que às objeções às regras basicamente formais do discurso - mas, sobretudo com a objeção fundamental de que, dessa maneira, o teórico pisa um terreno que deveria ser deixado aos participantes, principalmente porque o papel destes permanece a qualquer tempo aberto para o teórico. E isto ocorre justamente porque as

88 SCHAUER, Frederick. Balancing, Subsumption, and the Constraining Role of Legal Text. Op.cit., p. 09.

89 ALEXY, Robert. Teoria da Argumentação Jurídica: a teoria do discurso racional como teoria da justificação jurídica. Op. cit., p.90. Nas palavras do autor: A suposição da existência de uma única resposta adequada para cada questão prática coloca uma tese ontológica que não é apenas difícil de fundamentar como também não é muito plausível. Ainda que não exclusivamente, as respostas às questões práticas também se baseiam essencialmente em interpretações e avaliações de interesses. Não se pode supor, com base nisso, que sempre só é possível exatamente uma resposta para cada questão prática. A tese da existência de uma única resposta adequada para cada questão prática coloca, pelo menos no campo prático, uma injustificável ficção ontológica....... Isso apenas pressupõe que é possível haver questões práticas para as quais uma resposta pode ser descrita como única adequada no discurso, e que não há certeza de quais questões são essas, de modo que valha a pena tentar encontrar uma única resposta adequada. A isto subjaz uma concepção procedimental absoluta de adequação...... O conceito procedimental absoluto de adequação exige, ao contrário, que se continue a procurar uma única resposta. 
convicções normativas de cada teórico não podem ser assumidas como em geral mais adequadas do que as dos participantes 90 .

A partir daqui a conclusão do autor resta mais lógica ainda, eis que as regras do discurso racional prático, em tal acepção, não prescreveriam premissas a partir das quais partiram as partes discursantes, mas tão somente definiriam um processo de tomada de decisão, no qual há incertezas quanto o que deve tomar parte da base da decisão - enquanto que nas regras do discurso racional jurídico haverá estas bases (direitos fundamentais, constitucionais, etc.) 91 -, e nem todos os passos estariam prescritos de forma clara e absoluta.

Agora isto não pode levar a teoria do discurso para um campo de relativismos absolutos, isto porque a investigação discursiva, ainda que não leve à certeza matemática e absoluta, oportuniza pelo menos a sair do campo da mera opinião e da crença subjetiva, viabilizando-se, então, o conceito de adequação discursiva relativa, proposta por Alexy, isto tanto para o sopesamento de princípios como de regras jurídicas no âmbito de suas aplicações práticas 92 .

Por tais razões Alexy sustenta, com o que concordo, que a relação entre a teoria da argumentação jurídica com a argumentação prática geral não pode ser concebida a partir da idéia de subordinação da primeira em relação à segunda (sempre que houver casos em que a solução não possa ser derivada conclusivamente da lei, o discurso jurídico não passa de um discurso prático geral por trás de uma fachada jurídica); tampouco pode estabelecer relação de suplementação de uma em relação à outra (a argumentação jurídica só poderia ir até uma parte do caminho, chegando a um ponto em que os argumentos especificamente jurídicos não seriam mais disponíveis, intervindo a partir daí a argumentação prática em geral); mas que deve haver uma relação de integração

90 Idem, p.92. Alexy já dissera isto antes, ao sustentar que uma teoria da argumentação jurídica deve estar preocupada, pois, em entender e explicar como e quando uma afirmação normativa é racionalmente justificável. In ALEXY, Robert. Teoria da Argumentação Jurídica: a teoria do discurso racional como teoria da justificação jurídica. Op.cit., p.27.

91 Para Alexy: o discurso legal pode ser distinguido do discurso prático geral pelo fato de que o primeiro, em resumo, é restrito em seu objetivo pelo estatuto, pelos precedentes e pela dogmática legal e - no caso dos procedimentos judiciais -, pela legislação e regulamentações processuais. Idem, p.29. E por que tais restrições? Pelo reconhecimento: (a) do amplo alcance do que é meramente possível discursivamente; (b) da natureza experimental de quaisquer conclusões; (c) da necessidade de resolver muitas questões prática num espaço de tempo curto.

92 Novamente Schauer chama a atenção para o fato de que the open-ended premises of a proportionality argument are admissible in legal discourse generally, and we see such open-ended selection of premises, factors, and considerations not only in proportionality arguments, but also in common law adjudication. In SCHAUER, Frederick. Balancing, Subsumption, and the Constraining Role of Legal Text. Op.cit., p.11. Ver também o excelente texto do autor: SCHAUER, Frederick. The nature of customary law: legal, historical and philosophical perspectives. New York: Amanda Perreau-Saussine \& James Bernard Murphy eds., 2007. 
entre estas duas argumentações, no sentido de que argumentos jurídicos e práticos em geral se combinem em todos os níveis, aplicando-se conjuntamente93.

Observando-se tais parâmetros hermenêuticos, parece-me que a decisão política ou judicial pode até gerar equívocos de avaliação e interpretação por parte do decisor, mas não estará fundada em procedimento autoritário ou meramente subjetivo impossível de ser controlado.

\section{REFERÊNCIAS}

AARNIO, A. The rational as reasonable. A treatise of legal justification. Dordrecht etc.: Reidel, 1987

ALEXY, Robert \& PAULSON, Stanley \& PAULSON, Bonnie. The Argument from Injustice: A Reply to Legal Positivism. London: Oxford, 2010.

ALEXY, Robert. A argumentação jurídica como discurso racional. In: TEIXEIRA, Anderson Vichinkeski; OLIVEIRA, Elton Somensi de Oliveira (Orgs.). Correntes Contemporâneas do Pensamento Jurídico. São Paulo: Manole, 2010.

. A Discourse-Theoretical Conception of Practical Reason. In Ratio Juris 5, (3):231-251, 1992.

. A theory of legal argumentation: the theory of rational discourse as theory of legal justification. In Ratio Juris,vol.37. New York: Hammel, 2010.

. Die Idee einer prozeduralen Theorie der juristischen Argumentation. In Rechtstheorie, caderno 2,1981.

. Os Direitos Fundamentais e a Democracia no Paradigma Procedimental do Direito de Jürgen Habermas. In FRANKENBERG, Günter \& MOREIRA, Luiz. Jürgen Habermas: 80 anos. Rio de Janeiro: Lúmen Júris, 2009.

ALEXY, Robert. Teoria da Argumentação Jurídica: a teoria do discurso racional como teoria da justificação jurídica. São Paulo: Landy, 2001.

. Teoria de los Derechos Fundamentales. Madrid: Centro de Estúdios Constitucionales, 1990.

. The Construction of Constitutional Rights. In Law \& Ethics of Human Rights, Volume 4, Issue 1. Article 2. Berkeley: Berkeley Electronic Press, 2010.

ANDRONICO, Alberto. Ermeneutica e diritto da Wilhelm Dilthey ed Emilio Betti. In Spicchi di Novecento, a cura di Bruno Montanari. Roma: Giappichelli, 2008.

93 Idem, p.30. 
ATIENZA, Manuel. As razoes do direito. Teorias da Argumentação Jurídica. São Paulo: Landy, 2000.

BARROS, Diana Luz Pessoa de. Teoria do Discurso: fundamentos semióticos. São Paulo: Humanitas/USP, 2002.

BARTHES, Roland. Empire of Signs. New York: Hill and Wang, 1982.

. The Pleasure of the Text. New York: Hill and Wang, 1975.

CELANO, Bernardo. Dialettica della giustificazione pratica. Torino: Giappichelli, 2008.

CHOMSKY, Noam. Diálogos com Mitsou Ronat. São Paulo : Cultrix, 2000.

CHRISTOFOLETTI, Rogério. Por um estatuto epistemológico da análise do discurso. Revista de Estudos Lingüísticos, Belo Horizonte, v.8, n.1, p.171-181, jan./jun.1999.

COLEMAN, John. La pratica dei principi. In difesa di un approccio pragmatista alla teoria del diritto. Bologna: II Mulino, 2006.

DELFINO, Lúcio. Jurisprudência e o fumo: Uma guinada em prol dos interesses do fumante. In http://www.adital.com.br/site/noticia.asp?lang=PT\&cod=29646, acessado em 12/02/2009.

DOSSE, François. História do Estruturalismo. v. 2. São Paulo: Unicamp, 1994.

FERREIRA, Maria Cristina Leandro. Nas trilhas do discurso : a propósito de leitura, sentido e interpretação. In : ORLANDI,E.(org.) A leitura e os leitores. Campinas : Pontes, 1998. p. 201-208.

FOUCAULT, Michel. As palavras e as coisas. São Paulo : Martins Fontes, 1987.

GADET, F. \& HAK, T.(orgs.). Por uma análise automática do discurso: uma introdução à obra de Michel Pêcheux. Campinas : Editora da Unicamp, 1990.

GADET, Françoise. Saussure: une science de la langue. Paris: Presses Universitaires de France, 1987.

GALLO, Solange. Discurso, Escrita e Ensino. Campinas: Editora da Unicamp, 1994.

GIANFORMAGGIO. Luciano. Filosofia del diritto e ragionamento giuridico, a cura di E. Diciotti e V. Velluzzi, Giappichelli, Torino, 2008.

GROSSO, Enrico. Cittadinanza e vita democratica dell'Unione tra democrazia rappresentativa e democrazia partecipativa.. In LUCARELLI, Alberto (a cura di). Quaderni della Rassegna di Diritto Pubblico Europeo, vol. I. Napoli: Edizioni Scientifiche Italiane, 2008.

GUASTINI, Ricardo. Le fonti del diritto e l'interpretazione. Milano: Giuffrè, 1993.

. Teoria e dogmatica delle fonti. Milano: Giuffré, 1998.

GUNTHER, Kress. From Saussure to critical sociolinguistics. In WETHERELL, Margaret. Discourse Theory and Practice: A Reader. London: Sage Publications, 2001. 
HABERMAS, Jürgen. Between Facts and Norms. Contributions to a Discourse Theory of Law and Democracy. Cambridge, Mass.: The MIT Press. 1995.

Direito e Democracia: entre facticidade e validade. Vol. I. Rio de Janeiro: Tempo Brasileiro, 2003.

Moral Consciousness and Communicative action. Cambridge (Mass): The MIT Press, 1989.

HABERMAS, Jürgen. Três Modelos Normativos de Democracia. In HABERMAS, Jürgen. A Inclusão do Outro: estudos de teoria política. São Paulo: Loyola, 2002.

HERGET, James E. Contemporary German Legal Philosophy. Philadelphia: University of Pennsylvania Press, 1996.

INDURSKY, Freda \& FERREIRA, M.Cristina Leandro(orgs.). Os múltiplos territórios da Análise do Discurso. Porto Alegre : Sagra-Luzzatto, 1999.

INVERNIZZI, Gabriela. Substância nociva - Souza Cruz é condenada a indenizar família de fumante. Revista Consultor Jurídico, 2007. In http://www.conjur.com.br/.

JESTAEDT, Matthias. Die Abwägungslehre - ihre Stärken und ihre Schwächen. In Staat im Wort: Festschrift für Josef Isensee 253, 260, 262-63, 275, 2007.

$\mathrm{KOCH}$, Hans- Joachim \& RüSSMAN, Helmut. Juristische Begrúndungslehre, p. 48 e segs. e 112; NEUMANN, Ulfrid. luristische Argumentationslehre.

LACLAU, Ernesto. Philosophical roots of discourse theory. New York: Oxford University Press, 2001.

LEAL, Rogério Gesta. Condições e possibilidades eficaciais dos Direitos Fundamentais Sociais: os desafios do Poder Judiciário no Brasil. Porto Alegre: Livraria do Advogado, 2009.

A Decisão Judicial: elementos teórico-constitutivos à efetivação pragmática dos Direitos Fundamentais. Chapecó: Unoesc, 2012.

MACCORMICK, Neil and SUMMERS, Ronald .S. Interpreting statutes. A comparative study. AIdershot etc.: Dartmouth, 2005.

. Legal reasoning and legal theory. Oxford: Clarendon Press, 2000.

. Ragionamento giuridico e teoria del diritto. Torino: Giappichelli, 2001.

MANIACI, Giorgio. Note sulla teoria del bilanciamento di Robert Alexy. In Rivista Diritto\&questioni pubbliche, vol. 2, agosto 2002. Palermo: Università degli Studi di Palermo, 2002.

MENGONI, Luiggi. Ermeneutica e dogmatica giuridica. Milano: Giuffrè, 2006.

MOUFFE, Chantal. Deliberative Democracy or Agonistic Pluralism? 
OLIVEIRA, Amanda Flávio de. Direito de (não) fumar: uma abordagem humanista. Rio de Janeiro: Renovar, 2008.

ORLANDI, Eni. Interpretação. Petrópolis: Vozes, 1996.

PASTORES, Karina e BUCHALL, Anna Paula. A Marca da morte nos cigarros. Revista VEJA, Edição n¹.735 (2002). Disponível no site http://www.veja.com.br/ .

PÊCHEUX, Michel. Semântica e Discurso. Campinas : Ed. da Unicamp, 1988.

PECZENIK, A. On law and reason. Dordrecht etc.: Kluwer, 1989.

POSCHER, Ralf. Einsichten, Irrtümer und Selbstmißverständnisse der Prinzipientheorie. In Die Prinzipientheorie der Grundrechte: studien zur grundrechtstheorie Robert Alexys. 59, 65, 70 (Jan-R. Sieckmann ed., 2007); e o de KLEMENT, Jan Henrik. Vom Nutzen einer Theorie, die alles erklärt, 63. Juristenzeitung 756, 760, 2008.

RAZ, Joseph. Legal Principles and the Limits of Law, in "Yale Law Journal”, 81, 1972.

ROSEMBERG, José. Nicotina. Droga universal. São Paulo: SES/CVE, 2003.

SCHAUER, Frederick. Balancing, Subsumption, and the Constraining Role of Legal Text. In Law \& Ethics of Human Rights Review, vol. 4, Issue 1. Berkeley: Berkeley Electronic Press, 2010.

. The nature of customary law: legal, historical and philosophical perspectives. New York: Amanda Perreau-Saussine \& James Bernard Murphy eds., 2007.

STOCO, Rui. Tratado de Responsabilidade Civil. São Paulo: Revista dos Tribunais, 2007.

TARELLO, Giovanni. L'interpretazione della legge. Roma: Giuffrè, 2010.

TEIXEIRA, Marlene. Análise de Discurso e Psicanálise. Porto Alegre: EDIPUCRS, 2000.

VIOLA, Francesco \& ZACCARIA, Giancarlo. Diritto e interpretazione. Lineamenti di teoria ermeneutica del diritto. Roma-Bari: Laterza, 2009.

WINDSCHEID, Bernhard. Lehrbuch des Pandektenrechts, p.111: Die Endentscheidung ist das Resultat einer Rechnung, bei welcher die Rechtsbegriffe die Faktoren sind.

WRÓBLEWSKI, Jonh. The judicial application of law. Edited by Z. Bankowski and N. MacCormick. Dordrecht: Kluwer, 2001.

ZIZEK, Slavoy. Enjoy Your Symptom. London: Routledge, 1992. 